\title{
Multicriteria Choice Processes: An Application of Public Choice Theory to Bakke, the FCG, and the Courts*
}

\author{
Matthew L. Spitzer ${ }^{\dagger}$
}

Kenneth Arrow's 1951 work, Social Choice and Individual Values, 1 started a new field of social science, usually called "public choice."2 From the beginning, public choice scholars have examined alternative democratic processes for making societal decisions. ${ }^{3}$ Public choice theory assumes that each citizen has preferences about alternative social policies. The fundamental task is to investigate the process used to combine these individual preferences into a social choice. Arrow's theorem demonstrates that democratic methods of social decisionmaking fail to meet some conditions that seem desirable for any such process. ${ }^{4}$

A public choice theory approach can be applied to the decision processes of courts and administrative agencies. When a court or agency purports to select one of many possible outcomes by ranking the outcomes under a set of criteria, the situation parallels the democratic process. In place of the preferences of individual citizens, rankings

- The author gratefully acknowledges the valuable assistance and comments of Professor Michael Levine of the California Institute of Technology and the University of Southern California Law Center; Professors Charles Plott, John Ferejohn, Roger Noll, and James Quirk of the California Institute of Technology; Professor Allan Schwartz of the University of Southern California Law Center; Professor Steven Matthews of the University of Illinois; and Jean Spitzer, whose effort on this article's final draft made its production possible.

+ Member, California Bar.

1. K. Arrow, Social Choice and Individual Valufs (2d ed. 1963).

2. Prior to Kenneth Arrow's seminal work, the literature on the theory of public choice contained only a "few items." Id. at vii. Today there is enough literature in the area to justify calling public choice "a separate field." Mueller, Public Choice: A Survey, $14 \mathrm{~J}$. Econ. Literature 395, 395 (1976); see id. at $424-33$ (listing over 200 articles and books in or closely related to social choice field from 1951 to 1976 ).

3. Arrow focused directly on the problem of whether particular types of processes for making societal decisions by combining individual preferences meet certain rationality conditions that serve as attractive constraints for social decisionmaking processes. See $\mathrm{K}$. ARrow, supra note 1 , at 2, 22-33. For discussions of public choice theory accessible to the layman, see R. Musgrave \& P. Musgrave, Public Finance in Theory and Practice 102-26 (2d ed. 1976); A. Sen, Collective Choice and Social Welfare (1970).

4. See K. Arrow, supra note 1, at 2-3, 59.60; R. Musgrave \& P. Musgrave, supra note 3 , at 104-06; A. SEN, supra note 3, at 35-46. 
under criteria determine judicial or administrative choices. This article will use public choice theory to demonstrate that some administrative decision processes cannot possess all of the qualities that either are claimed by the agencies involved or are required by law. It also considers the applicability of public choice theory to judicial decisionmaking. The existing public choice literature appears to have neglected such an analysis. ${ }^{\bar{x}}$

In the recent case of Regents of the University of California $v$. $B a k k e_{,}{ }^{6}$ the Supreme Court examined procedures that use a set of criteria to select applicants for admission to medical school. In his opinion, Justice Powell found the admissions system at issue unconstitutionally discriminatory, but suggested that one such procedure, still involving race as a criterion, would be constitutional. ${ }^{7}$ Four members of the Court (in an opinion hereafter referred to as the "Brennan opinion") attacked Justice Powell's suggestions, claiming that his alternative process was not significantly different because it would merely permit decisionmakers to achieve the same result "in a manner that is not immediately apparent to the public." 8 Application of public choice theory to alternative methods for choosing medical school classes can offer insight into the choice process suggested by Justice Powell and also demonstrate the usefulness of the theory for analysis of administrative and legal decision processes. Part $I$ of this article uses the medical school admissions context to explain a particular form of public choice analysis. It also demonstrates that Justice Powell's proposed admissions process must violate at least one of a specified set of axiomatic characterizations of that process, and that the most likely violation directly supports the critique in the "Brennan opinion."

Part II applies public choice analysis to the hearing process used by the Federal Communications Commission (FCC) to choose a broadcast licensee from among competing applicants. It demonstrates that the process is internally inconsistent, and explores interpretations of the ap-

5. In Mueller's 1976 collection of social choice literature there are no sources that concern themselves primarily with agency and judicial decisionmaking processes. See Mueller, supra note 2, at 424-33. Although one recent article discusses the possible application of public choice analysis to juries, multiple judge courts, and administrative agencies, Levine \& Plott, Agenda Influence and its Implications, 63 VA. L. REv. 561, 563, 592-96 (1977), the article applies existing theory to voting in settings other than legislatures or popular elections. This article focuses on how substantive decision elements in the form of "criteria" are combined into a choice, rather than on how votes representing the preferences of individuals are combined into a collective choice.

6. 98 S. Ct. 2733 (1978).

7. Id. at 2762-66 (Powell, J., announcing judgment of court).

8. Id. at 2794 (opinion of Brennan, White, Marshall, and Blackmun, JJ., concurring in judgment in part and dissenting). 
parent inconsistency, as an illustration of the consequences of the analysis for administrative decision processes. Part III considers the application of public choice analysis to judicial decision processes and contrasts the implications of the theory in this setting with the conclusions previously reached concerning administrative agencies.

\section{Internally Inconsistent Multicriteria Choice Processes- An Explication Focusing on the Bakke Decision}

\section{A. Introduction}

A multicriteria choice process (MCCP) is a method of choosing a single alternative from many. Three steps characterize an MCCP. First, the decisionmaker defines or is given a finite set of relevant criteria. Second, alternatives are ranked under each of the criteria. Finally, the rankings are combined to generate a choice.

College, graduate, and professional school admissions can be conducted by using an MCCP. In the Bakke case, Justice Powell put forward the Harvard College admissions program as "[a]n illuminating example" of a choice process that includes race as a criterion in a constitutionally permissible way. ${ }^{9}$ As described in the Powell opinion, the Harvard program does not assure racial diversity by setting aside a fixed number of places for minorities, as the University of California at Davis Medical School had done. Instead, the Harvard program looks at many criteria to assure diversity in its student body. After Harvard chooses about one-seventh of a class on the basis of the single criterion of intellectual potential, "diversity" is the primary concern in selecting the rest of the class from the large group of remaining applicants who are academically admissible. ${ }^{10}$ The "diversity" judgment is made with "a number of criteria in mind"11 including intellectual potential, athletic and artistic talent, strength of character, family background, geographic origin, intended field of study, intended occupation, and membership in "disadvantaged economic, racial [or] ethnic groups."12 The comparative value of a high ranking in any one criterion is influenced by the prevalence of high rankings in that criterion by previously admitted applicants; ${ }^{13}$ the goal is to create a diverse class.

9. Id. at 2762 .

10. Id. at 2765 app. (opinion of Powell, J.).

11. Id. at 2766 app.

12. Id. at 2765 app. These criteria do not comprise an exhaustive list; they are garnered from the description of the Harvard program in the appendix to Justice Powell's opinion. See id. at 2765-66 app.

13. Id. at 2766 app. 
The Harvard program uses an MCCP. A set of criteria are identified, applicants are ranked under those criteria, ${ }^{14}$ and the rankings combine to dictate a choice. It also seems clear that, at least in filling the last few places in the class, the process is designed to choose additional members one by one from the pool of applicants remaining. ${ }^{15}$

\section{B. A Class of Internally Inconsistent MCCPs}

This section examines whether an MCCP can conform consistently to a given set of principles or constraints. The first step in the analysis is to choose nine "axioms." Each axiom either characterizes the operation of a wide range of real-world MCCPs or represents a normative principle that is often imposed on the MCCP. The nine axioms yield an internally inconsistent MCCP in the sense that it is not possible for all nine axioms to characterize the MCCP at the same time. ${ }^{16}$ Given an MCCP that satisfies some of the axioms, one knows that the process must violate at least one of the remaining axioms. By examining the Harvard program as an MCCP, one gains insight into the dialogue among the justices in the Bakke case. This discussion of the Harvard program illustrates the nine axioms in a simple context and serves as a prelude to more complicated treatment of the axioms in their relation to administrative and judicial decisionmaking.

\section{Axiom I: The MCCP chooses one alternative from a pool of al- ternatives.}

This axiom requires that a choice process operate by selecting a single most desirable candidate from the pool of candidates. ${ }^{17}$ Even

14. Although all of the listed criteria are considered with the goal of "diversity" in mind, diversity apparently does not determine all the rankings under each criterion and thereby reduce the process to a single criterion choice process. The continued emphasis on excellence in the description of the Harvard program, see id. at 2766 app., suggests that applicants with higher intellectual potential or more striking artistic talents would be preferred, all other aspects being equal, over competing applicants. Thus Harvard would not choose applicants that were less talented than alternative applicants in order to obtain a more "diverse" spectrum of abilities in the incoming class. Cf. note 47 infra (determination of ranking under single criterion may itself be product of MCCP).

15. See $98 \mathrm{~S}$. Ct. at 2766 app. (opinion of Powell, J.). This passage contains an example that suggests a one-by-one choice process. Although one of the facts in the example is that the admissions committee has "only a few [remaining] places left to fill," the example is meant to be a general illustration of how race enters as a factor in the admissions process. Id.

16. In the appendices, see pp. 768-78 infra, the roman numeral axioms in text arc translated into a set of arabic-numbered axioms and then a rigorous proof of the inconsistency of the axioms is carried out. In Appendix A, see pp. 765-68 infra, the proof is explained by relating it to previous, well-known results in public choice theory. Appendix $\mathrm{D}$, see pp. 778-79 infra, lists the roman numeral axioms for convenient reference.

17. See pp. 768-79 infra. 
when more than one candidate is ultimately chosen, as in the selection of a college or medical school class, this axiom is still satisfied if the group chosen is increased by successively adding the best candidate from the remaining alternatives. In an admissions program, one-by-one addition usually occurs at least for the candidates chosen from a "waiting list." Presumably this waiting list represents a sequential ordering by desirability of the best prospects from the pool of candidates that have not already been accepted. ${ }^{18}$

2. Axiom II: There are at least three "potential alternatives," each of which would be chosen if available and if no better alternative were a possible choice.

This axiom asserts that the world contains at least three minimally qualified candidates, but makes no claim respecting the number of candidates that are actually alternatives in the choice process. ${ }^{19} \mathrm{~A}$ minimally qualified candidate is one who would be chosen if there were no available better candidate. A candidate who is not minimally qualified will not be chosen even if there are no alternative candidates available. Axiom II is satisfied in the case of medical schools and universities that have more minimally qualified candidates than places to be filled. ${ }^{20}$

3. Axiom III: The choice process can consider any conceivable "potential alternative," regardless of its particular characteristics.

In the context of an admissions MCCP, this axiom means that any minimally qualified candidate can be considered for a position in the class. $^{21}$

4. Axiom IV: The MCCP uses no absolute scales or absolute weights to combine categorical rankings into a choice.

This axiom precludes the use of either absolute scales, which translate rankings within criteria into units of an absolute preference, or absolute weights, which compare and combine the size of preferences

18. The University of California at Davis Medical School used such a waiting list. Sce Regents of Univ. of Cal. v. Bakke, 98 S. Ct. 2733, 2740 (1978) (opinion of Powell, J.).

19. See p. 769 infra.

20. The Harvard program defines the central admissions "dilemma" as that of "choosing among a large number of "qualified' candidates." $98 \mathrm{~S}$. Ct. at 2765 app. (opinion of Powell, J.). "Qualified"" apparently means " "admissible" and able to do "adequate work at Harvard." Id.

21. See p. 769 infra. 
under different criteria. ${ }^{22}$ When absolute scales or absolute weights are used, the MCCP may combine rankings under various criteria into a ranking under a single criterion that is decisive. For example, a medical school admissions process that selects a class by a formula that combines Medical College Admissions Test (MCAT) score, college grade-point average, and numerical scores recorded by interviewers into a single numerical score violates axiom IV.

A choice process may, without violating axiom IV, involve the use of scaled or quantitative comparisons between applicants within a single criterion. "Quarternary" comparisons, such as "with respect to criterion one, $\mathrm{A}$ is preferred to $\mathrm{B}$ twice as strongly as $\mathrm{C}$ is preferred to $D^{\prime}$ are acceptable under axiom IV. Only the use of some absolute method of comparison between criteria violates the axiom.

The use of absolute weights or absolute scales need not be in the form of a comprehensive and explicit quantitative formula in order to violate axiom IV. Admissions officers might combine criteria by unstated, informal rules of thumb. They might, for example, recognize membership in racially or economically disadvantaged groups by adding standard numbers of points to a candidate's MCAT scores. In effect, two criteria would be measured on the same absolute scale of MCAT points.

5. Axiom $V$ : Given any two alternatives $A$ and $B, A$ will be a more desirable alternative than $B$, or $B$ will be a more desirable alternative than $A$, or $A$ and $B$ will be equally desirable alternatives. The more desirable of the two must be chosen if one is more desirable than the other.

The first part of this axiom is technically described as the existence of a "complete binary relation." ${ }^{23}$ The choice process must be able to compare alternatives in pairs. Although some pairs of alternatives may be equally desirable, a complete binary relation exists unless there are pairs that cannot be compared at all. ${ }^{24}$ The second part of the axiom simply constrains the decisionmaker to choose the more desirable of two unequal alternatives.

An admissions program would probably claim to abide by axiom $\mathrm{V}$. Admissions officers are unlikely to confess an inability to form preferences, including indifference, between candidates and they would

22. See pp. 769.70 infra.

23. See pp. 770-71 infra.

24. See A. SEN, supra note 3 , at 3 (indifference between pairs of candidates is to be distinguished from inability to compare pairs of candidates at all; only latter indicates absence of "complete binary relation"). 
recognize that selection of the less desirable candidate of a pair would be irrational.

\section{Axiom VI: No one criterion totally dominates the MCCP.}

A criterion totally dominates an MCCP if, for all possible pairs of candidates, the candidate who ranks higher under a particular criterion will be chosen regardless of the rankings under other criteria that supposedly enter into the choice process. If axiom VI is violated, rankings under a single criterion determine the choice between any pair of candidates. ${ }^{25}$

As long as a single criterion would not be decisive in every possible case, axiom VI will not be violated. The axiom can still apply if the choice within certain categories of candidates is made on the basis of a single criterion. For example, admitting a medical school class strictly on the basis of MCATs would involve using a single criterion choice process, but choosing between white applicants from high-income backgrounds solely on the basis of MCATs, while using multiple criteria to choose candidates for admission from other groups, would not involve such a process.

7. Axiom VII: For any set of alternatives, the choice process will have the same result whether the choice is made directly from the entire set or is made from a set of preliminary winners chosen from subsets comprising the entire set.

This principle means that "agenda" influences will not affect the outcome of the MCCP. ${ }^{26}$ Suppose, for example, that three candidates are being considered for admission to college and that the admissions committee operates under the rule that one candidate will be preferred to another if the first candidate ranks higher under two out of three criteria used in the MCCP. ${ }^{27}$ Suppose, in addition, that the committee chooses a candidate by successively comparing pairs of candidates-the "winner" of each pairwise comparison is compared against a candidate from among those who have not yet been considered. If candidates display certain rankings under the three criteria, the agenda alone will

25. See p. 771 infra.

26. See id.

27. This example is often used to illustrate that decision by majority vote will not necessarily be consistent from one occasion to the next even though the same issue is voted on and the voters have the same preferences. See, e.g., K. Arrow, supra note 1, at 2-3; R. MusGrave \&. P. MusGrave, supra note 3, at 106. This "voting paradox" is altered for the purposes of this article by replacing voters with criteria. 
determine the winner. Suppose the candidates are A, B, and C and that the rankings under the three criteria are as follows:

$\begin{array}{lccc}\text { Ranking } & \text { Criterion 1 } & \text { Criterion 2 } & \text { Criterion 3 } \\ \text { Best } & \text { A } & \text { B } & \text { C } \\ \text { Middle } & \text { B } & \text { C } & \text { A } \\ \text { Worst } & \text { C } & \text { A } & \text { B }\end{array}$

Any of the three candidates can be chosen, depending on which pair of candidates is compared first:

$\begin{array}{lclc} & \text { Winner of } & & \\ \text { First Pair } & \text { First Pair } & \text { Second Pair } & \text { Overall Winner } \\ \text { A versus B } & \text { A } & \text { A versus C } & \text { C } \\ \text { B versus C } & \text { B } & \text { B versus A } & \text { A } \\ \text { A versus C } & \text { C } & \text { C versus B } & \text { B }\end{array}$

An admissions process that operated in this fashion would violate axiom VII because in some situations the agenda would influence the choice between candidates. ${ }^{28}$

It is unlikely that admissions committees have analyzed possible agenda influences in their selection processes. It seems safe to assume that, if asked, most committees would agree that agenda influences should not have any effect on the choice between candidates. A contrary assertion would admit that substantive criteria do not alone determine which candidate will be chosen.

8. Axiom VIII: For every possible set of alternatives, if one member of the set ranks higher than a second member in every criterion used in the choice process, then the second member will not be chosen.

Axiom VIII precludes the choice of an alternative that is inferior to

28. This type of admissions process can also violate other axioms. Suppose the rankings of four candidates under three criteria are as follows:

$\begin{array}{lccc}\text { Ranking } & \text { Criterion 1 } & \text { Criterion 2 } & \text { Criterion 3 } \\ \text { First } & \text { X } & \text { X } & \text { W } \\ \text { Second } & \text { X } & \text { W } & \text { Z } \\ \text { Third } & \text { W } & \text { Z } & \text { Y } \\ \text { Fourth } & \text { Z } & \text { Y } & \text { X }\end{array}$

Suppose that in the first pairwise comparison $W$ is compared to $X ; X$ would emerge the winner of that comparison. Suppose that $\mathrm{X}$ is then compared to $\mathrm{Y} ; \mathrm{Y}$ would be the winner of that comparison, but $Z$ would emerge as the choice after being compared with $Y$ in the final pairwise comparison. $Z$, however, is inferior to $W$ under every criterion. A choice process that selects a candidate when there is another candidate superior under every criterion violates axiom VIII. See pp. 724-25 infra. 
another alternative under every criterion. ${ }^{29}$ Admissions MCCPs combine desirable applicant characteristics into a choice. If two candidates are equal under all criteria but one, then the candidate that is superior under the remaining criterion would be more desirable. Hence, if candidate $\mathrm{A}$ is superior to candidate $\mathrm{B}$ under every criterion, $\mathrm{A}$ is a more desirable candidate than $\mathrm{B}$. Rationality requires that $\mathrm{B}$ not be chosen when a totally superior candidate, $A$, is available. All admissions committees would claim, if asked, that this axiom characterizes their MCCP.

9. Axiom IX: For any two alternatives, $A$ and $B$, construct their comparative categorical rankings. If there are any other two alternatives, $C$ and $D$, where $C$ has the same comparative rankings relative to $D$ as $A$ has to $B$, and $D$ is not chosen over $C$, then $B$ is not chosen over $A$.

Axiom IX requires that switching a candidate's social security number and other irrelevant characteristics not alter the choice..$^{30}$ Most admissions officers would claim that this axiom characterizes their own choice process, i.e., that supposedly irrelevant criteria do not influence the choice between candidates. ${ }^{31}$

\section{The Analytic Use of the Internal Inconsistency Result}

The appendices contain a proof of a "possibility theorem"32 establishing that an MCCP cannot simultaneously satisfy all nine axioms. ${ }^{33}$ The possibility theorem aids in the analysis of MCCPs in three ways. First, the law may require that an MCCP satisfy all nine axioms or institutions may claim that one does so. An awareness of the possibility

\section{See $\mathbf{p} 772$ infra.}

The analysis of MCCPs in this article focuses on a single step in which one candidate is chosen. Axiom VIII precludes the choice of candidate $B$ when another candidate, $A$, is superior to $B$ under every criterion. If $A$ is chosen in one step, in the next step $B$ could be chosen without violating axiom VIII, because $A$ would no longer be in the pool of candidates. See pp. 720-21 supra.

30. See p. 772 infra.

31. The examination here focuses on the admissions process at a particular period in time, such as one year. It is clear that criteria change complexion or are added over time. See Regents of Univ. of Cal. v. Bakke, $98 \mathrm{~S}$. Ct. 2733, 2765-66 app. (1978) (opinion of Powell, J.) ("concept of diversity" expanded recently in Harvard program to make it desirable that each class contain nontrivial numbers of students from "disadvantaged cconomic, racial and ethnic groups"). It is assumed for purposes of determining the applicability of axiom IX that the criteria and their significance in the admissions process remain fixed over the period when a particular class is chosen.

32. Even though the theorem demonstrates that it is impossible for certain processes to satisfy certain axioms simultaneously, it is of a type that is referred to as "possibility theorems." See A. SEN, supra note 3, at 37-40; Mueller, stifra note 2, at 420.

33. See pp. 720-25 supra (discussing axioms); note 16 supra (summarizing appendices). 
theorem allows one to say for certain that at least one of the claims or legal requirements is not satisfied by the $\mathrm{MCCP} .^{34}$

Second, some of the axioms are more likely to be violated than others. $^{35}$ By examining the probability that each particular axiom is violated, some idea about the ways in which the MCCP under examination departs from institutional claims or legal requirements can be formed. For example, if it is known that a particular process satisfies axioms I-VIII, one knows that axiom IX is violated and can conclude that identical cases may not be decided the same way, ${ }^{36}$ or that influences not captured by the criteria are affecting the outcome. ${ }^{37}$ If axioms I-V and VII-IX are satisfied, one knows that axiom VI is violated and choices are determined by the outcome under a single criterion. ${ }^{33}$

Finally, when an MCCP claims to satisfy all nine axioms, the possibility theorem is useful in analyzing proposed reforms. Reforms that do not propose an acceptable violation of at least one axiom will leave the process in a form that is unable to satisfy at least one institutional claim or legal requirement. However, if the MCCP can use absolute weights or rely on a single criterion, in violation of axioms $\mathrm{IV}^{30}$ or $\mathrm{VI}^{40}$ respectively, then the process will not be internally inconsistent under the possibility theorem..$^{41}$

\section{Application of the Analysis to the Bakke Case}

The possibility theorem ${ }^{42}$ can be applied in two ways to the choice processes discussed in Bakke. First, the theorem can help illuminate the probable operation of some of the admissions programs discussed in the case. Second, the theorem can offer insight into the substance of the debate within the Court about the constitutionality of various admissions processes.

34. The possibility theorem holds only that at least one of the nine axioms must be violated. Any particular MCCP may violate more than one axiom.

35. For example, when an axiom is a legal requirement and it is easy to detect a violation of the axiom, the axiom is not likely to be violated. On the other hand, the violation of some axioms may be virtually impossible to detect and therefore may be more likels: See pp. $745-48$ infra.

36. See note 31 supra (MCCPs can change over time; axiom IX focuses on one point in time).

37. See p. 725 supra.

38. See p. 723 supra.

39. See pp. 721-22 supra.

40. See p. 723 supra.

41. The process may still be internally inconsistent for entirely separate reasons.

42. See pp. 720-25 supra. 


\section{Analyzing the Harvard Program Under the Nine Axioms}

Eight of the nine axioms seem to apply to the Harvard program. In at least part of the admissions process, the program seems to employ an $\mathrm{MCCP}^{43}$ that satisfies axiom I by making a series of choices of single applicants from the pool of remaining applicants. ${ }^{44}$ Because there are at least three minimally qualified potential applicants when each choice is made, axiom II is satisfied. ${ }^{45}$ Because the admissions process places no apparent restrictions on the characteristics of applicants, axiom III appears to be satisfied. ${ }^{4 \mathfrak{C}}$ Since no single criterion dominates the selection of the last six-sevenths of the class, at least that part of the admissions process satisfies axiom VI. ${ }^{47}$ Axioms V, VII, VIII, and IX all are either highly plausible or highly desirable characteristics of an admissions process: the process will be able to decide that it either favors one of two candidates or is indifferent between them and a more desirable candidate will be chosen over one who is less desirable; the "agenda" will not influence the outcome; a candidate will not be chosen if there is another candidate available for the same slot who is superior to the first candidate under every criterion; and "irrelevant" criteria will have no effect. ${ }^{48}$

Of the nine axioms, axiom IV is the only one that is neither explicitly imposed by the Harvard program nor a plausible or desirable characteristic of the admissions process. The material cited in the Powell opinion does not say that the program uses some kind of absolute scales or absolute weights to combine individual ratings under each criterion into a choice. ${ }^{49}$ Because the Harvard program probably satisfies the other eight axioms, ${ }^{50}$ however, axiom IV is probably

43. For a description of the Harvard program as an MCCP, see pp. 719-20 supra.

44. See pp. $720-21$ supra.

45. See p. 721 supra.

46. $I d$.

47. See p. 723 supra.

According to the description of the Harvard program in Bakke, roughly one-seventh of the class is chosen on the basis of "intellectual potential" alone. $98 \mathrm{~S}$. Ct. at 2765 app. (opinion of Powell, J.). Determining the outcomes for the single criterion of intellectual potential, however, may itself involve an MCCP. If it does, then the elements of that MCCP combined with the elements of the MCCP used to choose the remaining sixsevenths of the class comprise a composite MCCP that is used to determine the choice of the entire class.

48. See pp. $722-25$ supra.

49. See $98 \mathrm{~S}$. Ct. at 2762-66 app.

It can therefore be assumed, for present purposes, that Justice Powell was referring to a process in which there are no absolute scales or absolute weights.

50. This statement must be qualified in three respects. First, it is arguable that Harvard selects the last six-sevenths of the class based on the single criterion of "diversity," in violation of axiom VI. But see note 14 supra ("diversity" not single criterion in Harvard program).

The second qualification goes to the question of whether Harvard uses a finite number 
violated. In choosing each additional member of a class, with knowledge of the characteristics of those already admitted, the admissions committee must use a system that establishes the relative importance of the various criteria. This system need not be an explicit quantitative method of combining information on performance under each criterion; it may consist of unstated rules of thumb. ${ }^{51}$

\section{Harvard's Treatment of Race as a Criterion}

The description of the Harvard program states that in order for Harvard to offer "first-rate education to its students, minority representation in the undergraduate [student] body cannot be ignored." 52 It goes on to say that "there is some relationship between numbers [of blacks] and achieving the benefits to be derived from a diverse student body." 33 Furthermore, " 10 or 20 black students could not begin to bring to their classmates and to each other the variety of points of view, backgrounds and experiences of blacks in the United States." ${ }^{-4}$ Yet the description states that there are no "target-quotas for the number of blacks" set in the admissions process. ${ }^{55}$ In the conclusion of the statement one is given a hypothetical example of a choice between three applicants to "help to illustrate the kind of significance attached to race." 56 The lesson of the hypothetical is meant to be that "the critical criteria are often individual qualities or experience not dependent upon race but sometimes associated with it." 57

of criteria in its decision process. If the choice criteria are infinite in number or unspecified even as rough categories, then the admissions process is not a true MCCP. See pp. 719 . 20 supra. The description of the Harvard program, however, states that the admissions committee proceeds "with a number of criteria in mind." $98 \mathrm{~S}$. Ct. at 2766 app. (opinion of Powell, J.). That statement suggests a choice process based on a finite number of criteria. In addition, many of the criteria considered secm well-defined but broad enough to choose a multifaceted college class. See p. 719 supra (listing criteria). Unfortunately, the description does not provide enough information for one to determine whether there is a finite set of criteria. See $98 \mathrm{~S}$. Ct. at 2762-66 app. (opinion of Powell, J.).

A final qualification involves the question of whether the Harvard program satisfics axiom I. There is evidence that at least part of the process operates as a one-by-one choice of members of the class. See p. 720 supra. Unfortunately, again, the materials give insufficient information to determine for certain whether axiom $I$ applies.

51. See pp. 721-22 supra.

52. $98 \mathrm{~S}$. Ct. at 2765 app. (opinion of Powell, J.).

53. Id. at 2766 app.

54. Id. at 2765-66 app.

55. Id. at 2765 app.

56. Id. at 2766 app.

57. Id. The hypothetical is as follows:

The Admissions Committee, with only a few places left to fill, might find itself forced to choose between $A$, the child of a successful black physician in an academic community with promise of superior academic performance, and B, a black who grew up in an inner-city ghetto of semi-literate parents whose academic achievement was lower 


\section{Multicriteria Choice Processes}

After reading the hypothetical, one is tempted to concur with Justice Powell's assertion that race "is simply one element-to be weighed fairly against other elements-in the selection process" so that the constitutionally fatal "facial intent to discriminate" 58 evident in the Davis Medical School "quotas" is absent. Yet the hypothetical assumes there are "few [remaining] places to fill" in the class. ${ }^{50}$ By that point, the admissions committee would presumably have admitted significant numbers of blacks. Otherwise, Harvard could not fulfill its goal of sufficient minority representation to assure "first-rate education to its students." "10 As a result, the weight given to minority status would be lower than it would be if much of the class had been admitted but the college was far short of its goal of sufficient minority representation. ${ }^{61}$

The possibility theorem suggests that, in extreme circumstances, the Harvard program would act as if it admits students under the following rule of thumb: "only blacks shall fill the remaining places in the class." If Harvard had admitted most of its class, but had admitted very few black students, there would be a large premium granted to black applicants. ${ }^{62}$ If the situation were extreme enough, then any minimally qualified black applicant might be preferred over any remaining nonblack applicant regardless of the nonblack applicant's other qualifications. Such machinations constitute an effective but imprecise quota. The probable violation of axiom IV suggests that this effective quota must be implemented through an absolute-weights or absolute-scale process at least in the form of rough rules of thumb.

\section{The "Brennan Opinion" Critique}

The "Brennan opinion" criticized Justice Powell's distinction between the Davis "quota" admissions policy and the Harvard program

but who had demonstrated energy and leadership as well as an apparently abiding interest in black power. If a good number of black students much like $A$ but few

like $B$ had already been admitted, the Committee might prefer B; and vice versa.

If $\mathrm{C}$, a white student with extraordinary artistic talent, were also seeking one of the Id.

remaining places, his unique quality might give him an edge over both $A$ and $B$.

58. Id. at 2763 .

59. Id. at 2766 app.

60. Id. at 2765 app.; see pp. 730-31 infra.

61. In an MCCP with absolute weights, it might seem logical that the weights themselves would not change to reflect the goal of racial diversity, but one of the criteria would take into account information about the number of candidates already admitted who belong to a disadvantaged group and about the number of spaces remaining to be filled in the class. For purposes of exposition, the weights have been described as changing, although one could view the weights themselves as fixed while a "racial diversity" criterion varies.

62. The amount of the premium would depend on the number of blacks already admitted to the class and on the number of spaces that remain to be filled. 
by hypothesizing an absolute-scale process designed to achieve approximately the same number of minority admissions as a "quota" system:" ${ }^{\text {B3 }}$

There is no sensible, and certainly no constitutional distinction between, for example, adding a set number of points to the admissions rating of disadvantaged minority applicants as an expression of the preference with the expectation that this will result in the admission of an approximately determined number of qualified minority applicants and setting a fixed number of places for such applicants as was done here. ${ }^{6.4}$

The high likelihood that the Harvard program violates axiom IV and uses an absolute scale or absolute weights suggests that this hypothetical is exactly on point. Public choice analysis only strengthens the criticisms in the "Brennan opinion" by suggesting that the weight given to membership in a disadvantaged group will be higher if the actual number of previously admitted applicants from the disadvantaged group is lower. Such a system would cause the automatic fulfillment of a rough quota.

Justice Powell also argued that the "Court would not assume that a university, professing to employ a facially nondiscriminatory admissions policy, would operate it as a cover for the functional equivalent of a quota system." 65 The Harvard program was Justice Powell's primary example of a process employing a facially nondiscriminatory admissions policy. ${ }^{66}$ Harvard's description of its admissions process combined with the analysis in this article suggests, however, that that program will operate as the functional equivalent of a quota system when circumstances demand such a system to achieve adequate minority representation. Since the Harvard admissions process probably employs a system of absolute weights or an absolute scale, further factual inquiry should be undertaken before drawing the sort of distinction

63. The "Brennan opinion" did not use the term "absolute scale" to characterize its hypothesized process. Against the background of the Davis program, in which each applicant's qualifications were reduced to a single numerical score, see $98 \mathrm{~S}$. Ct. at 2740 (opinion of Powell, J.), however, the process hypothesized in the "Brennan opinion" suggests an absolute scale. In a Davis-type process, disadvantaged minority applicants presumably would receive enough points added to their "rating" so that they would constitute the desired proportion of the final admitted class. The idea of combining each applicant's qualifications into a single numerical rating strongly suggests an absolute scale process because each quality, including membership in a disadvantaged minority group, is transferred onto the same scale of points.

64. Id. at 2794 (opinion of Brennan, White, Marshall, and Blackmun, JJ., concurring in judgment in part and dissenting) (footnote omitted).

65. Id. at 2763.

66. The only other example that Justice Powell referred to was Princeton's undergraduate admissions program which he described as being "similar" to Harvard's. See id. at $2762 \mathrm{n} .51$. 
that Justice Powell does between the Harvard program and an admissions process that directly employs quotas. When an absolute scale or absolute weights underlie an admissions process, discovery of the exact nature of the scale or weights is the most important step in deciding whether the process meets constitutional standards. Justice Powell's facial constitutionality test only would be appropriate for hypothetical processes not subject to examination at the trial level. ${ }^{67}$ Finally, the fact that an absolute scale or absolute weights probably are used at Harvard, but are hidden from view, supports the "Brennan opinion" view that Harvard's program approximates the Davis quota system; as the opinion states, the only difference is that the Harvard program "proceeds in a manner that is not immediately apparent to the public" since it "does not ... make public the extent of the preference [for minority students] and the precise workings of the system." 68 The "Brennan opinion" captured most of the results that can be achieved by an application of public choice theory to admissions processes. In the administrative area, however, the defects of particular decision processes have not been as apparent to judges and commentators.

\section{The Use of Internally Inconsistent Multicriteria Choice Processes by Administrative Agencies}

Administrative agencies sometimes use MCCPs to make regulatory decisions. ${ }^{69}$ This discussion focuses on FCC use of an MCCP in initial

67. Justice Stevens emphasized that the focus of the case should be on the Davis process. See id. at 2809-10 (Stevens, J., concurring in judgment in part and dissenting in part). Because the case could be decided based on federal statutes and the facts about the Davis admissions process, Justice Stevens found that no consideration should properly have been given to admissions programs not before the Court. See id. at 2809-10, 2815.

68. Id. at 2794 .

It has been asserted that decision processes that hide the actual mechanics of decision may be desirable when a decision involves a clash of fundamental values. Resolving the issue explicitly would involve the painful choice of one value over another when both are held dear. See G. Calabresi \& P. Bobbitt, Tragic Choices 24-26, 57-58 (1978). Justice Powell cited as one reason for holding a quota system unconstitutional the fact that such a system "will be viewed as inherently unfair by the public generally as well as by ap. plicants for admission," since "[f]airness in individual competition, . . . especially [for benefits] provided by the State, is a widely cherished American ethic." 98 S. Ct. at 2763 n.53 (emphasis added). But see Calabresi, Bakke: Lost Candor, N.Y. Times, July 6, 1978, at Al9, col. 3 (conflict between equality-of-opportunity ethic and goal of reparations for past bias should not justify subterfuge in admissions process; subterfuge should be reserved for situations in which "irreconcilable fundamental principles are at stake and openly affirming one value destroys the other").

69. Although FCC initial broadcast licensing is the only example discussed extensively in this article, there are other instances of MCCPs used by administrative agencies. For example, until recently, the Civil Aeronautics Board (CAB) used an MCCP to award domestic airline routes. Although the Federal Aviation Act of 1958 directed the $\mathrm{CAB}$ to 
broadcast licensing comparative hearings ("comparative hearings") to select one broadcaster from a set of candidates for the exclusive right to broadcast over a particular wavelength in a particular region. Although the focus is on one kind of regulation by one agency, the same type of analysis can generate similar policy conclusions about MCCPs used by other administrative agencies.

This discussion first describes FCC comparative hearings and then demonstrates that each of the nine axioms described previously are either physical constraints or legal requirements for the hearing process. Since public choice theory dictates that the hearing process cannot obey all of the axioms, the second part of this section discusses the likelihood that the MCCP violates particular axioms and the legal and normative implications of the violations; it concludes by using the analysis previously developed to evaluate various proposals to reform FCC comparative hearings.

\section{A. FCC Initial Broadcast Licensing Comparative Hearings and the Applicability of the Nine Axioms}

\section{The FCC Initial Broadcast Licensing Comparative Hearing Process as an MCCP}

The FCC has allocated the broadcast spectrum to various uses, including radio and television transmission. The Commission has allocated radio and television channels to communities throughout the United States. ${ }^{70}$ Since only one broadcaster can use a frequency in a

authorize service on any route as "required by the public convenience and necessity," 49 U.S.C. $\$ 1371(1970)$, the Board has often withheld route authority from all but one applicant. See, e.g., Chicago-New Orleans Nonstop Route Proceeding, 2 Av. L. REP. (CCH) I 22,234 (1977); Chicago-Montreal Route Proceeding, 2 Av. L. ReP. (CCH) \ 22,224 (1976).

The $\mathrm{CAB}$ awarded routes on the basis of a set of criteria, including the number of passengers who would receive service for the first time, the strength of a challenge to a foreign carrier, the amount of revenue diverted from existing carriers, the total beyondarea benefits, and the need for carrier strengthening. See, e.g., Phoenix-Des Moines/ Milwaukee Route Proceeding, 2 Av. L. REP. (CCH) 22,255.02, at 15,051-54 (1978); Chicago-Montreal Route Proceeding, 2 Av. L. REP. (CCH) 22,224 , at 14,875 (1976). Rankings under each criterion were combined to pick authorized carriers.

Recent changes in the operations of the $\mathrm{CAB}$ have made this description obsolete, sce Message from the President of the United States, Airline Deregulation, H.R. Doc. No. 92, 95th Cong., Ist Sess. (1977), and the CAB's authority to restrict the number of airlines serving particular routes will lapse altogether on December 31, 1981, Airline Deregulation Act of 1978, Pub. L. No. 95-504, $\$ 40$ (a), 92 Stat. 1744 (to be codified in 49 U.S.C. $\$ 1601$ ).

70. See National Broadcasting Co. v. United States, 319 U.S. 190, 210-13 (1946); 47 C.F.R. $\$ 73.202$ (1977) (FM radio); id. $\$ 73.606$ (television); Anthony, Towards Simplicily and Rationality in Comparative Broadcast Licensing Proceedings, 24 Stan. L. Rev. 1, 7-10 (1971). 
particular region at any given time, the FCC must often pick a single licensee from among several applicants. When no legally qualified broadcaster wishes to renew an existing license for a particular frequency, the Commission grants an "initial broadcast license" for the frequency. ${ }^{71}$ The Commission's choice process employs an MCCP and is divided into application and hearing phases.

In the application phase, the FCC determines whether or not applicants meet minimal qualifications for receiving a license. ${ }^{72}$ In making that determination, the FCC's Broadcast Bureau scrutinizes applicants for legal, ${ }^{73}$ financial, ${ }^{74}$ technical, ${ }^{75}$ and moral $^{70}$ soundness. In addition, the Bureau reviews other factors related to the "public interest," including program service plans, concentration of control of the mass media, and any allegations of an applicant's anticompetitive or monopolistic practices. ${ }^{77}$ After these preliminary evaluations, every application is forwarded to the Chief of the Broadcast Bureau who

71. Until recently, the FCC treated hearings involving competition between a broadcaster wishing to renew a license and broadcasters wishing to obtain the license for the first time quite differently from hearings involving only initial licensing. See Anthony, supra note 70, at 106-10. "Renewal" hearings in which potential new licensees take part have now become similar to initial broadcast hearings in their governing standards and procedures. See In re Formulation of Policies Relating to the Broadcast Renewal Applicant, Stemming from the Comparative Hearing Process, 66 F.C.C.2d 419, 430 (1977) (if applicant meets certain standards of past performance that are higher than those minimally required for renewal, then renewal may follow without making comparison with other applicants for license; otherwise renewal candidate will be considered in normal comparative hearing except that renewal candidate will be favored to some degree on basis of "legitimate renewal expectancy"). The Supreme Court, however, has recently held that the Commission may use different standards in comparative renewal hearings than in initial broadcast licensing comparative hearings. See FCC v. National Citizens Comm. for Broadcasting, 436 U.S. 775, 810-11 (1978).

The discussion in this article is limited to the choice process used to select a licensee in initial broadcast licensing comparative hearings. Technically, the procedures described in this article apply only to granting the right to construct a broadcast facility. The right to broadcast over the facility, however, is routinely granted once construction has been completed. Anthony, supra note 70 , at 11 . As a result, this article will treat comparative construction permit hearings as comparative license hearings.

72. The application phase limits consideration at the hearing phase to "potential alternatives" in the sense of axiom II. See p. 721 supra ("potential alternative" or "minimally qualified candidate" is one who will be chosen if no other alternatives or candidates are available); p. 769 infra (technical definition of potential alternative); Anthony, supra note 70 , at 34 .

73. See, e.g., 47 U.S.C. $\$ 310$ (b) (Supp. V 1975) (requiring applicant, its directors, officers, partners, and four-fifths of its stockholders to be United States citizens); 47 C.F.R. $\$ 73.35$ (1977) (applicant may not own any AM radio or television station in same market as AM station that is being awarded).

74. See Anthony, supra note 70, at 18-19.

75. See $i d$. at 18 (technical factors include availability of frequency, coverage and clarity of signal, studio location, antenna location, and equipment requirements).

76. See id. at 19.

77. See id. at 19-24. 
designates the set of minimally qualified applicants for a comparative hearing before a hearing examiner. ${ }^{i s}$

In the hearing phase, the FCC selects a single licensee from this set of qualified applicants. The relevant federal statute, the Communications Act of $1934,{ }^{79}$ provides meager guidance for choosing a licensee. The statute merely states that the FCC shall grant a license to an applicant if the Commission finds "that the public convenience, interest or necessity would be served" by such a grant. ${ }^{80}$ The courts and the FCC have understood this language as mandating the selection "on a comparative basis" of the applicant who will best serve the public interest. ${ }^{81}$ In response to this vague mandate, the FCC created an MCCP for choosing among applicants in a comparative hearing. The Commission's 1965 Policy Statement on Comparative Broadcast Hearings ${ }^{82}$ describes the MCCP and lists six criteria that are intended to dictate the choice between minimally qualified applicants for an initial broadcast license. ${ }^{83}$

The six criteria are diversification of control of the media, integration of ownership and management, proposed program service, past broadcast record, likely degree of efficiency in use of the frequency, and character. The 1965 policy statement describes the diversification criterion as "a factor of primary significance." $\$ 4$ The diversification criterion rests on the belief that diffusing control of the mass communication media will produce an increased flow of information to the public. $^{85}$ Under this criterion, an applicant who does not own or control any other media interests will be preferred to one who does. An applicant who has existing media interests is further disfavored under the diversification criterion to the extent that his interests "are larger,

78. Id. at 34. If some question arises as to the minimal qualifications of one or more of the applicants, the applications may be routed through the full Commission before being sent to a hearing examiner. $I d$.

79. 47 U.S.C. $\$ \$ 151-609$ (1970 \& Supp. V 1975).

80. Id. $\$ 309(\mathrm{a})$.

81. Ulysses Sherman Bartmess \& W.H. Hansen, 35 Fed. Reg. 16,064-65 (1970); see note 139 infra (citing cases).

82. 1 F.C.C.2d 393 (1965) [hereinafter cited as 1965 Policy Statement].

83. The two goals that shaped the FCC's choice of criteria were "first, the best practicable service to the public, and, second, a maximum diffusion of control of the media of mass communications." Id. at 394 .

In addition to the six criteria listed in text, the FCC may insert "other factors" into comparative hearings. Id. at 399 . The cxistence of other factors in particular hearings does not affect the analysis. One is merely faced with an MCCP that has more than six criteria. In addition, a leading commentator on the FCC comparative hearing process has stated that use of "other factors" is "rare." Anthony, supra note 70, at 43.

84. 1965 Policy Statement, supra note 82, at 394.

85. See id. at 394 n. 4 . 
i.e., go towards complete ownership and control."86 Such interests are also more detrimental to the degree that they are in media "in, or close to, the community being applied for," or are "significant" because they reach large numbers of people in a locality or extend to regional or national coverage. ${ }^{37}$

The 1965 policy statement attributes "substantial importance" to the factor of "integration of ownership and management." 88 This criterion reflects the view that owner participation in station management increases a station's responsiveness to its legal duties and to the broadcast area's changing needs. ${ }^{89}$ Accordingly, an applicant that plans to integrate ownership and management will be preferred to one that does not. The number and nature of the factors used to discriminate between applicants under the integration criterion may, however, make ranking applicants difficult..$^{90}$ For example, an owner's full-time participation is greatly preferred to part-time work, ${ }^{91}$ but the importance of an owner's work will depend on his actual activities at the station, his past broadcast experience, and his residence within the broadcast area. ${ }^{92}$

In its 1965 policy statement the FCC admitted that, although program service is crucially important to the public, "[t]he feasibility of making a comparative evaluation is not so obvious." ${ }^{33}$ The FCC expects each applicant to ascertain the broadcast needs of the community and to design an adequate program plan for those needs. In the absence of "material and substantial differences between applicants' proposed program plans," 94 however, the Commission gives no weight to this criterion. ${ }^{95}$

Another criterion employed by the FCC concerns the applicant's performance in previous ownership or management of a broadcast station. When the Commission evaluates this criterion of "past broadcast record," it is seeking an indication of the applicant's likely future performance. Although the FCC will disregard a past broadcast record within the bounds of average performance, ${ }^{96}$ it will consider both unusually good and unusually poor records.

86. Id. at 395 .

87. Id. at 395-96.

88. Id.

89. Id.

90. See Anthony, supra note 70, at 29 n.169.

91. See 1965 Policy Statement, supra note 82 , at 395 .

92. See id. at $395-96$.

93. Id.

94. $I d$.

95. Id.

96. Id. at 398. 
The final two criteria are likely efficiency in using the frequency and the applicant's character. The FCG will favor an applicant proposing technically superior service. ${ }^{97}$ It will disfavor applicants with serious character deficiencies, ${ }^{98}$ but will disregard character considerations in the absence of such serious defects..$^{99}$

The FCC ranks the applicants under each of the applicable criteria, sometimes ranking ordinally ${ }^{100}$ and sometimes hinting at preference size. ${ }^{101}$ Finally, the rankings are combined, in some undefined manner, to choose a licensee. The 1965 policy statement states that the process is "inherently complex" and that "the subject does not lend itself to precise categorization or to the clear making of precedent." 102 Furthermore, the Commission asserts that the various criteria "cannot be assigned absolute values." ${ }^{103}$ The importance of any one criterion is only determinable "upon consideration of the circumstances and conditions before us in an actual hearing case." 104

\section{Different Ways in which the Axioms Can Apply to an Administrative Process}

Particular axioms can constrain an administrative process in several ways. First, an axiom can be a "physical constraint," a constraint imposed not by human institutions but by technological or natural limitations. For example, it is not physically possible with present technology for two broadcasters to share the same frequency at the same time in the same region. Thus, the FCC must grant only one broadcast license for each frequency in a region at a given time.100

"Explicit legal constraints" and "implicit legal constraints" are two

97. See id. at $398-99$.

98. Id. at 399 .

99. See id. The general exclusion of character evidence is intended to prevent an applicant from turning "the hearing into a search for his opponents' minor blemishes, no matter how remote in the past or how insignificant." Id.

100. An ordinal ranking is one that specifies the order in which applicants are ranked but gives no other information. A ranking that is constructed by assigning each applicant a number expressing how much that applicant is preferred is a "cardinal," as opposed to ordinal, ranking.

101. See, e.g., Mid-Florida Television Corp., 33 F.C.C.2d 1, 21 (1972) (specification of degree of preference for some applicants over others under various criteria as "small" or as "substantial"); WHDH, Inc., 22 F.C.C. 767, 860.61 (1957) (under civic participation criterion, two applicants entitled to "some preference" over third applicant and to "significant preference" over fourth applicant).

102. 1965 Policy Statement, supra note 82, at 393.

103. Id.

104. WHDH, Inc., 22 F.C.C. $767,858-59$ (1957).

105. Note that the FCC's MCCP could theoretically choose more than one applicant to receive a license. In such a case, the FCC would have to resort to means other than its MCCP to narrow the field to one applicant. See note 117 infra (axiom requiring that MCCP choose only one applicant from any group of applicants is not physical constraint). 
other kinds of axiomatic limitations on administrative agencies. A legal constraint is explicit when courts have indicated that an agency must obey the constraint. Implicit legal constraints are easily constructed extrapolations of present legal doctrine that have never been considered explicitly by courts. ${ }^{106}$ This second type of constraint is important because administrative agencies and courts will sometimes not have cause to consider or explicate various aspects of agency decisionmaking with the degree of rigor required for application of highly

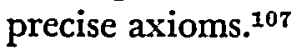

Three kinds of legal principles are particularly important in the analysis of FCC comparative hearings. The Commission must (l) comply with the statutory provisions that establish and govern it; ${ }^{108}$ (2) use procedures that meet the minimal standards of procedural due

106. See, e.g., pp. 743-44 infra (arguments, by extrapolation from physical and explicit legal constraints, that axioms VII and VIII are implicit legal constraints on FCC).

Although implicit legal constraints are based on extrapolations from existing legal principle, and have never actually been imposed by courts, they are acceptable as binding constraints under the theory that existing legal principle is to be taken seriously because courts derive their legitimacy in a democracy from making principled decisions. See notes 211 \& 235 infra.

As understood here, explicit legal constraints embody a legal realist's conception of the role of law in society, i.e., "law" as an expression of courts' holdings, and nothing more. See Holmes, The Path of the Law, 10 Harv. L. Rev. 457, 457 (1897) (object of study of law is "prediction of the incidence of the public force through the instrumentality of the courts"). Alternatively, implicit legal constraints, relying as they do upon an evaluation of the FCC's statutory mandate, institutional setting, and relation to the courts, reflect a far broader notion of what is law in our society. It may nevertheless be true that even legal realists will ultimately have to see the FCC's implicit legal constraints as "law." This change would be the result of the new, activist role that the D.C. Circuit has been playing with respect to the FCC. See, e.g., Central Fla. Enterprises, Inc. v. FCC, 4 MediA L. REP. (BNA) 1502 (D.C. Cir. Sept. 25, 1978), amended, No. 76-1742 (D.C. Cir. Jan. 12, 1979) (renewal hearing). Since all of the implicit constraints discussed here are easily linked to accepted legal rules, it seems likely that they would be enforced by the D.C. Circuit in an appropriate case.

Only one who argued that the law is nothing more than an expression of what the courts have actually done and are actually likely to do would claim that some of the axioms are not properly called "law." Such a person would see the implicit constraints as merely elements that must be hidden in the FCC's opinion writing process in order for the opinion to escape reversal.

107. Sometimes this effect results from the technical nature of the axioms. See p. 743 \& note 147 infra (unlikely that agencies or courts have ever considered impact of "agenda" influences on institutional decisionmaking processes). In other situations, an axiom may cxpress a principle that is so obviously inherent in a decision process that it may never be considered explicitly. See note 151 infra (principle that candidate inferior to another under all criteria used will not be chosen may be so obvious as never to be considered). The difficulties inherent in applying axioms to real-world institutions have been recognized elsewhere. See Plott, Axiomatic Social Choice Theory: An Overview and Interpretation, 20 AM. J. Political Scr. 511, 555 (1976) (need usually to focus on models of processes rather than real-world processes themselves; "only a few [real-world] processes can be modeled with the degree of precision required by [axiomatic] methods").

108. See, e.g., FCC v. Pottsville Broadcasting Co., 309 U.S. 134, $144-45$ (1940); Greater Boston Television Corp. v. FCC, $44 \pm$ F.2d 841, 850-51 (D.C. Cir. 1970). 
process; ${ }^{109}$ and (3) avoid decisions that are arbitrary and capricious, i.e., lacking any reason to support them. ${ }^{110}$

The procedural due process standards include the requirement that an agency cannot ignore its own precedents and previously enunciated policies. It must either adhere to the precedents and policies or explain the reasons for departing from them. ${ }^{111}$ The FCC therefore must honor previous claims about its decisionmaking process made in case law or in policy statements. ${ }^{112}$ Although the claims may have been imposed by the FCC on itself, they operate as legal constraints.

The principle that agency decisions must not be "arbitrary and capricious" requires that an agency use "reasoned decisionmaking." Whether the decisions are made in adjudication or policymaking, a reasoned basis must be provided.113 The United States Court of Appeals for the District of Columbia, the court with exclusive jurisdiction to hear appeals from FCC comparative hearings, ${ }^{114}$ has stated that "reasoned decisionmaking" as opposed to "bidding" or "chance" must be the basis of choices between potential licensees, even "when a certificating agency is required to choose between two or more applicants endowed with virtually equivalent qualifications."115

109. See Greater Boston Television Corp. v. FCC, 444 F.2d 841, 851 (D.C. Cir. 1970).

110. See id.; Administrative Procedure Act $\$ 10(\mathrm{e})(\mathrm{B})(1), 5$ U.S.C. $\$ 706(2)(\mathrm{A})$ (1976).

111. See, e.g., Environmental Defense Fund, Inc. v. EPA, 510 F.2d 1292, 1299 (D.C. Cir. 1975) ("an agency is not required to adhere to a prior policy with iron rigidity" but law requires that agency "explain the reasons for its modification"); UAW v. NLRB, 459 F.2d 1329, 1341 (D.C. Cir. 1972) (principle that "agency must either conform to its own precedents or explain its departure from them" is "elementary tenet of administrative law").

112. See, e.g., Pasadena Broadcasting Co. v. FCC, 555 F.2d 1046, $1051-52$ \& n.45 (D.C. Cir. 1977) (FCC cannot examine only single criterion of technical efficiency in granting initial license; doing so would be departure from long-settled precedent mandating that multiple criteria be examined); Greater Boston Television Corp. v. FCC, 444 F.2d 841, 852 (D.C. Cir. 1970) (dictum) (special judicial vigilance required when agency changes its policies; agency "must supply a reasoned analysis indicating that prior policies and standards are being deliberately changed, not casually ignored").

113. See, e.g., Permian Basin Area Rate Cases, 390 U.S. 747, 792 (1968) (rate setting must be done only after "reasoned consideration ... of the pertinent factors"); Rhode Island Consumers' Council v. FPC, 504 F.2d 203, 210 (D.C. Cir. 1974) (record only vaguely describes reasons for agency action; it must "disclose with unmistakable clarity the reasons" for action).

The requirement that changes in policy or departures from precedent must be accompanied by "reasoned decisionmaking" is distinct from the previous point that an agency must follow the rules and policies that it has enunciated. The reasoned decisionmaking requirement restricts the ways by which an agency can change its policies, even when it does so openly.

114. 47 U.S.C. $\$ 402(\mathrm{~b})$ (1970); see Citizens Committee to Save WEFM v. FCC, 506 F.2d 246, 266 (D.C. Cir. 1974).

115. Greater Boston Television Corp. v. FCC, 444 F.2d 841, 852 (D.C. Cir. 1970) (dictum). 


\section{The Applicability of the Nine Axioms to FCC Comparative Broadcast Licensing Hearings}

It is not difficult to demonstrate that each of the nine axioms discussed above is a physical or legal constraint on FCC comparative hearings. Axiom I requires the FCC to choose only one licensee for any given broadcast license. ${ }^{116}$ The axiom, for example, eliminates any MCCP that selects several "winners" and then randomly chooses one of them to receive the license. This requirement is an explicit legal constraint on the choice process, ${ }^{117}$ which must proceed by reasoned distinctions and not by "chance" even when the applicants being compared are nearly identical. The District of Columbia Circuit has mandated that, between two applicants, comparative hearings "must reveal which would better" serve the public interest. ${ }^{118}$ Since two applicants cannot simultaneously "better" serve the public interest, the FCC's MCCP must choose exactly one winning licensee on the basis of substantive "public interest" considerations contained in the criteria.

Axiom II requires that there be at least three minimally qualified potential applicants for each initial licensing decision. ${ }^{119}$ Because the axiom speaks of potential applicants, it is not necessary that three minimally qualified applicants actually apply. There need only be at least three minimally qualified possible applicants in the world. This requirement is necessarily satisfied because any given region contains a large number of minimally qualified potential applicants for a broadcast license. ${ }^{120}$ In practice, FCC comparative hearings often include

116. See pp. $720-21$ supra.

117. The FCC is not physically constrained to use an MCCP that results in exactly one winner. It could use an MCCP that selected several of the applicants as winners and then choose one licensee from the set of "winning" applicants. This final choice, which would not be part of the MCCP, could be by lottery or by some other method not related to the MCCP.

118. Johnston Broadcasting Co. v. FCC, 175 F.2d 351, 356 (D.C. Cir. 1949) (emphasis added). Although Johnston Broadcasting was decided before the 1965 Policy Statement, supra note 82, the D.C. Circuit has subsequently stated that the case describes "the decisional process to be followed" in FCC comparative hearings. Star Television, Inc. v. FCC, 416 F.2d 1086, 1088 (D.C. Cir.), cert. denied, 396 U.S. 888 (1969). Although many of the principles stated in Johnston Broadcasting can be taken as dicta, the Commission secms to have adhered to the principles as scrupulously as to holdings in other cases. In discussing the fact that much of Johnston Broadcasting can be read as dicta, a leading commentator notes that nonetheless, "the Commission over the years seems to have observed the court's dicta as solicitiously as its narrow holdings, and it is hard to escape the impression that the court conceived its entire opinion [in Johnston Broadcasting] as a detailed set of instructions to the Commission." Anthony, supra note 70, at 110 (footnote omitted).

119. See p. 721 supra.

120. For example, any given region contains wealthy individuals of good character who do not have any connection with broadcasting. These individuals could apply for a license. They could, by employing the right individuals, establish a technically good, pro- 
three or more minimally qualified applicants as competing candidates. ${ }^{121}$

To satisfy axiom III, the choice process must be able to consider any conceivable minimally qualified applicant regardless of the characteristics it possesses. ${ }^{122}$ Because the FCC states that it will include any minimally qualified applicant in a comparative hearing, ${ }^{123}$ it appears that this axiom is satisfied in practice. Indeed, for the same reason, compliance with axiom III can be characterized as a legal requirement. The Commission must obey its own policy directives unless it announces a policy change openly and offers a reasoned explanation. ${ }^{124}$

Axiom IV forbids the use of absolute weights or absolute scales in combining categorical rankings into a choice. ${ }^{125}$ The FCC incorporates this axiom by presuming that criteria cannot be assigned "absolute values." 126 One commentator has described the process of combining outcomes on the different criteria as one of "subjective 'weighing," "127 because there are no absolute weights or absolute scales. ${ }^{128}$

gramatically responsive, and financially sound broadcasting company. In addition, the owners could live in the communities that received the broadcasts and could take an active role in the management of the station.

121. See, e.g., Mid-Florida Television Corp., 33 F.C.C.2d 1, 1.2 (1972) (five minimally qualified applicants); WHDH, Inc., 22 F.C.C. 767, 767-68 (1957) (four minimally qualified applicants).

122. See p. 721 supra.

123. See pp. 733-34 supra.

124. See p. 738 supra.

The courts will enforce the reasoned decisionmaking requirement. See pp. $742-43$ infra (use of single criterion in contravention of 1965 policy statement and without explanation is illegal and would not be tolerated by court); Central Fla. Enterprises, Inc. v. FCC, 4 Media L. Rep. (BNA) 1502, $1509-11$ (D.C. Cir. Sept. 25, 1978), amended, No. 761742 (D.C. Cir. Jan. 12, 1979) (renewal hearing) (FCC did not give adequate rationale for its decision; FCC orders vacated and case remanded to Commission).

125. See pp. 721-22 supra.

126. 1965 Policy Statement, supra note 82 , at 393 .

The FCC has designated three criteria as of "primary" or "substantial" importance. Anthony, supra note 70, at 42-43. As Anthony points out, however, there is no specification of which of the three criteria take precedence in case of conflict. $I d$. at 43 . In addition, there is no discussion of the relative importance of several other criteria. Yet these other criteria sometimes override the criteria described as primary. See id. at 43 \& n.248. Thus, the FCC's hints as to the relative importance of some of the criteria give little indication of relative importance in practice.

127. Id. at 42 .

128. See id. at 42-44:

Fundamental are the problems of subjectivity presented by the need to choose the winning applicants on the basis of multiple preferences drawn from multiple criteria. ... There is no comprehensive system of priorities that establishes whether or when or to what extent one kind of preference ... should have more weight than another. ... The decision makers thus lack principles to govern them in deciding whether the preferences [for] one applicant [on the criteria] outweigh those [for] another [on other criteria].

The complexities and uncertainties of reaching ultimate decision are carried even 
The 1965 policy statement and case law prior to it indicate a belief that use of absolute scales or absolute weights in comparative hearings would be impossible.129 Experience and the nature of the criteria themselves suggest that this belief is well founded. At times it has been extremely difficult for the FCC merely to rank applicants ordinally. ${ }^{130}$ In addition, the nature of the criteria seems to defy application of an absolute scale even to a single criterion. Each criterion breaks down into a large number of elements that are difficult to compare, and under any one element there is a large degree of variability in possible applicant characteristics. ${ }^{131}$ For example, the diversity criterion compares an applicant's existing media interests on the basis of extent of control, proximity to the community that the new licensee will serve, size and area of audience, significance of regional or national coverage, and significance with respect to other media. ${ }^{132}$

In any event, axiom IV, like axiom III, operates as a legal constraint on the FCC because there exists an announced policy against the assignment of absolute values to the various criteria. Until this policy is changed publicly, the Commission cannot legally grant licenses on the basis of a secret or open set of absolute weights or an absolute scale..$^{\mathbf{1 3 3}}$

Axiom $V$ requires that there be a complete binary relation ${ }^{134}$ within any possible set of minimally qualified potential applicants for each license, and that the MCCP choose a more desirable applicant over a

further by the fact that the preferences to be weighed are variable in size. This variability raises the problem of how to weigh against each other, for example, a "substantial" preference from one subject area and "moderate" or "slight" preferences awarded under other headings. ...

The Commission has established no principles or standards to govern this ultimate step [of weighing the preferences for one applicant under some criteria against the preferences for another under one criteria] in the decision process.

129. See p. 740 supra; Johnston Broadcasting Co. v. FCC, 175 F.2d 351, 357 (D.C. Cir. 1949) (there are "no essential absolutes" in comparing applicants; there are such absolutes for determining if applicants are minimally qualified).

130. See, e.g., Moline Television Corp., 31 F.C.C.2d 263, 284-87 (1971) (Johnson, Comm'r, dissenting) (renewal hearing) (renewal applicant should not have been ranked higher on past programming record criterion than new applicant; new applicant should have been given "substantial preference" under integration criterion); Flower City Television Corp., 9 F.C.C.2d 249, 262 (1967) (Johnson, Comm'r, dissenting) (disagreeing with majority's rankings under integration criterion).

131. See 1965 Policy Statement, supra note 82, at 393 ("differences between applicants with respect to each factor are almost infinitely variable"); Anthony, supra note 70, at 46 (absolute scale cannot be established for present criteria because consideration under each criterion involves too many variable factors).

132. 1965 Policy Statement, supra note 82, at 395 .

133. See p. 738 \& note 124 supra.

134. A "complete binary relation" exists when the decisionmaker can specify, between any two alternatives, that one is more desirable than the other or that the two are equally desirable. See p. 722 supra; pp. $770-71$ infra. 
less desirable one. ${ }^{135}$ The FCG is required to satisfy this axiom because of two explicit legal constraints. Under the principle of reasoned decisionmaking, the Commission must choose between applicants in some manner rationally related to its statutory duty to further the "public convenience, interest or necessity."136 In addition, it must choose only one applicant for any particular license. ${ }^{137}$ These two requirements are both satisfied only if the FCC is capable of determining which of any two potential applicants would better serve the public interest. If the Commission can make such a determination, there exists a complete binary relation within any possible set of potential applicants. ${ }^{138}$ Moreover, because the public interest must control every outcome, it would be unlawful for the FCC ever to select a less desirable candidate over a more desirable one. ${ }^{139}$

If the outcome under one criterion determines the outcome in all possible cases, axiom VI is violated. ${ }^{140}$ This axiom is embodied in an explicit legal constraint on the FCG. Appellate courts consistently require that the FCC consider all material differences between applicants raised by the parties in a comparative hearing. ${ }^{141}$ In a recent case, ${ }^{142}$ the District of Columbia Circuit referred to "long-settled precedent" 143 in rebuking the FCC for apparently deciding between applicants solely on the basis of the technical efficiency criterion. One applicant had been excluded from consideration solely because it proposed to broadcast a weaker signal than the other applicants. ${ }^{144}$ The court noted that the applicant's "other attributes might show that the

135. See pp. 722-23 supra.

136. 47 U.S.C. $\$ 307$ (a) (1970); see pp. $738-39$ supra (choice among applicants must proceed by reasoned distinctions; illegal to decide between applicants by chance).

137. See p. 739 supra.

138. In fact, there is more than a complete binary relation. Since the FCC must choose only one applicant by its MCCP, it must be able to establish a strict preference between any two applicants. Indifference as a result of a comparison would not allow the FCC to choose between two applicants.

139. See, e.g., National Broadcasting Co. v. United States, 319 U.S. 190, 215.17 (1943); FCC v. Pottsville Broadcasting Co., 309 U.S. 134, 138 n.2 (1940).

140. See p. 723 supra.

141. See, e.g., Greater Boston Television Corp. v. FCC, 444 F.2d 841, 851 (D.C. Cir. 1970), cert. denied, 403 U.S. 923 (1971); Scripps-Howard Radio, Inc. v. FCC, 189 F.2d 677, 680 (D.C. Cir.), cert. denied, 342 U.S. 830 (195I). The courts will not hesitate to overturn licensing decisions that ignore relevant criteria put at issue by the parties. See Citizen's Comm. to Save WEFM v. FCC, 506 F.2d 246, 262 (D.C. Cir. 1974) (FCC failed to give adequate consideration to program service criterion because it did not inquire into whether program format should be retained when it is "unique or otherwise serves a specialized audience that would feel its loss").

142. Pasadena Broadcasting Co. v. FCC, 555 F.2d 1046 (D.C. Cir. 1977).

143. Id. at 1051 .

144. Id. at 1048 . 
satisfaction accorded to those who will listen counterbalances, as far as the public interest is concerned, the fact that fewer could hear." $14 \bar{s}$

To satisfy axiom VII, the outcome of an MCCP must not be affected by a change in the "agenda" in any particular comparative hearing. ${ }^{146}$ Specifically, the choice from a set of minimally qualified applicants should be the same whether the choice is made directly from the whole set or the set is divided into subsets and an overall winner is chosen from the preliminary winners in each subset. There appear to be no FCC or court decisions dealing specifically with agenda influences. ${ }^{147}$ Axiom VII, however, is an implicit legal constraint following from the explicit legal requirement that the FCC choose applicants on the basis of the public interest ${ }^{148}$ and from the requirement that the FCC be able to specify which of any pair of minimally qualified applicants will better serve the public interest. ${ }^{149}$ Suppose that, under one agenda, applicant $A$ would be chosen while, under a second agenda, applicant $B$ would be chosen. Assuming that the FCC can determine that one of the two applicants will better serve the public interest, one of the agendas would not choose this preferred applicant. A failure to adhere to axiom VII would therefore be legally unacceptable.

Axiom VIII states that if there exists an applicant, A, who ranks higher than applicant B under every criterion, then applicant $B$ will not be granted the license. ${ }^{150}$ This requirement is an easy extrapolation from certain explicit legal constraints. ${ }^{151}$ When courts support an FCC initial license award that has been challenged as arbitrary or irrational, they usually first point to the winner's superiority over the challenger under certain criteria and then defer to the FCC's discretion in weighing and combining all of the criteria. ${ }^{152}$ But if the challenger were superior under all criteria, such judicial support for the FCC decision

145. Id. at 1053 .

146. See pp. 723-24 stupra; p. 771 infra.

147. Although agenda influences may be detectable by agencies and courts in some cases, see pp. 745.46 infra, the abstruse and technical nature of agenda influences make it unlikely that the FCC, the courts, or the public have considered the general problem of agenda influence on comparative hearings.

148. See pp. $738-39$ supra.

149. See pp. 739,742 supra.

150. See pp. 724-25 supra.

151. The lack of more explicit consideration by the FCC and by the courts of the principle inherent in axiom VIII is probably caused by a perception that failing to follow the principle would be a flagrant violation of the reasoned decisionmaking requirement. See p. 738 supra. Thus, axiom VIII may be so far within the core of the law that the FCC would not even consider violating it, at least explicitly.

152. See, e.g., Massachusetts Bay Telecasters, Inc. v. FCC, 261 F.2d 55, 64-65 (D.C. Cir. 1958), cert. denied, 366 U.S. 918 (1961); Pinellas Broadcasting Co. v. FCC, 230 F.2d 204, 205-06 (D.C. Cir.), cert. denied, 350 U.S. 1007 (1956). 
would be impossible. In addition, courts will overturn an FCC decision if the FCC has not considered all of the public interest criteria raised by the parties. ${ }^{153}$ If the FCC were to choose one applicant over another that is superior under every criterion, it would have ignored all of the criteria raised in the case. Such a decision would obviously be unlawful.

Axiom IX requires that, for any four applicants $A, B, C$, and $D$, if $C$ compares to $\mathrm{D}$ under the criteria as $\mathrm{A}$ compares to $\mathrm{B}$, and if $\mathrm{D}$ is not chosen over $C$, then $B$ will not be chosen over A. ${ }^{154}$ In essence, the axiom requires that an applicant's name or other irrelevant characteristics not affect the choice. Axiom IX is an explicit legal constraint on the FCC. If, in the hypothetical above, $\mathrm{D}$ were not chosen over $\mathrm{C}$ in one case, then in a subsequent case the FCC would have to follow the precedent and not choose B over A. ${ }^{155}$ The FCC could only ignore the precedent if it could make reasoned distinctions between the two cases. Yet if the two cases were identical under the public interest criteria, it would not be possible to make such distinctions. ${ }^{156}$

\section{B. Determining which Axiom is Likely to be Violated by FCC Comparative Hearings}

The possibility theorem indicates that the FCC's MCCP cannot simultaneously obey all nine axioms, even though all nine constitute legal or physical contraints on comparative hearings. It seems clear, therefore, that the FCC is legally required to use a choice process that has internally inconsistent properties. Although such a conclusion clashes with the principle that regulators and regulated parties should not be subjected to contradictory legal requirements, ${ }^{157}$ in practice, the Commission must be violating one or more of the axioms. The main task that remains is to determine which axioms are most likely to be violated.

Axiom II is a physical constraint that binds the FCC in choosing

153. See pp. $742-43$ \& note 141 supra.

154. See p. 725 supra.

155. See p. 738 supra. The general principle that the FCC must follow its own precedents or explain departures from them has been evident in the holdings of many recent cases. See, e.g., Garrett v. FCC, 513 F.2d 1056, 1060-61, 1063 (D.C. Cir. 1975) (FCC must adhere to its own precedents and reconcile its disposition with past decisional practice; case remanded with instruction that FCC reevaluate its decision in light of its own past precedents); Columbia Broadcasting Sys., Inc. v. FCC, 454 F.2d 1018, 1027 (D.C. Cir. 1971) (FCC's "utter failure to come to grips with" past precedents "constitutes an inexcusable departure from the essential requirement of reasoned decisionmaking").

156. In discussing axiom IX, the focus is on a single point in time. As a result, the same policies must be in force for both cases.

157. See L. Fuller, The Morality of LAw 69 (rev. ed. 1969) ("legislative carelessness about the jibe of statutes with one another can be very hurtful to legality"). 
broadcast licensees. ${ }^{158}$ Some of the remaining eight axioms are unlikely to be violated because such violations either would be easily detected by reviewing courts or would require blatant dishonesty on the part of the FCC. To violate axioms III, VI, or VIII and avoid judicial detection, for example, the FCC would probably have to include false information in its opinion. If the FCC were to violate axiom III by refusing to consider a qualified candidate, violate axiom VI by using a single criterion choice process, or violate axiom VIII by selecting a candidate inferior under all criteria, it could not admit this conduct openly without bringing about appellate reversal. ${ }^{150}$

It would also be extremely difficult to cover up violations of any of these three axioms. Since there is a body of rules and decisions concerning minimal qualifications, the Commission would have to fabricate an entire comparative hearing decision in order to avoid comparing any minimally qualified applicant to others as required by axiom III. ${ }^{100}$ If the same single criterion choice process were consistently employed for any period of time, the pattern of the cases would probably reveal that fact and, in each case, the FCC would have to "pretend" to be considering the other criteria. ${ }^{101}$ To violate axiom VIII, the FCC would have to distort the case enough to make plausible the selection of an applicant who was inferior under all criteria. ${ }^{162}$

It would be far easier for the FCC to violate axiom VII. In the abstract, the FCC's refusal to define precisely its choice process prevents any theoretical check on possible agenda influences. In practice, it is difficult to gauge the plausibility of either an inadvertent or deliberate violation of axiom VII. In most cases, there are relatively few ap-

158. See pp. 739-40 supra.

159. See pp. 742-43 supra (courts will overturn any FCC attempt to use single criterion choice process); pp. 743-44 supra (violation of axiom VIII would be more serious than other illegal administrative acts; axiom VIII is probably so deep within core of law that agency would not violate it).

160. At least one recent case indicates that courts will detect and overturn FCC decisions that are too implausible or depart too much from past precedents. See Central Fla. Enterprises, Inc. v. FCC, 4 Media L. REP. (BNA) 1502, 1516 (D.C. Cir. Sept. 25, 1978), amended, No. 76.1742 (D.C. Cir. Jan. 12, 1979) (renewal hearing) (FCC order "is unsupported by the record and the prior law on which it purported to rely").

161. An effort to "tell a story" in each case that directed attention away from the use of a single criterion choice process would involve assessment in opinions of criteria that were not given weight in the actual decision. Such an effort would almost certainly have to be conscious.

162. It is likely that if any significant distortion were involved, courts would detect it and vacate the FCC action. See Central Fla. Enterprises, Inc. v. FCC, 4 Media L. REP. (BNA) 1502, 1510 (D.C. Cir. Sept. 25, 1978), amended, No. 76-1742 (D.C. Cir. Jan. 12, 1979) (renewal hearing) (1965 policy statement "imposed an orderliness on the inquiry which made it obvious when applicants were not in fact on an equal footing"). 
plicants ${ }^{163}$ and the FCG should be able to detect the end result of agenda influences, at least when they lead to selection of an applicant who is clearly inferior to at least one other applicant. In such a situation, a reviewing court could also detect this result. It would, however, be unable to correct the underlying agenda influences, unless the FCC had made these influences plain in its decision. ${ }^{164}$ Moreover, if one of a group of quite similar applicants prevailed under the MCCP, deliberate or inadvertent agenda influences might be impossible for anyone to detect.

The situation is roughly the same for axioms I and V. Although it would probably be easy to detect a choice of a clearly inferior applicant resulting from a violation of either axiom, it would be difficult to determine which, if either, of these axioms had been violated. Even worse, it would be virtually impossible to detect any problem at all when the hearing compared a group of similar applicants. A violation of axiom I would mean that that the FCC does not rely entirely on the MCCP to choose one applicant. In some cases the FCC might use chance or legally irrelevant considerations to choose a final licensee. In order to do so, it would have to offer false reasons related to the public interest in support of its decision. The same kind of deception would be required to disguise the violation of axiom $\mathrm{V}$ that would take place if the FCC were unable to distinguish between roughly similar candidates on the basis of public interest considerations, ${ }^{165}$ or chose to select the less desirable of a pair of candidates. Yet, in any such case, it would be easy to emphasize minor differences between candidates and write a conclusory opinion that would pass muster. ${ }^{106}$

163. Although the FCC often considers three or more minimally qualified applicants for a particular license, the number rarely exceeds five or six for a particular case. See note 121 supra (citing cases).

164. FCC opinions usually indicate the rankings of the applicants under various criteria and give sequential overall comparisons of applicants to explain the choice made. See, e.g., Mid-Florida Television Corp., 33 F.C.C.2d 1, $21-22$ (1972); WHDH, Inc., 22 F.C.C. $767,881-82$ (1957). When only a few applicants are considered, it is difficult to imagine that an applicant who is clearly inferior to another would be chosen because of agenda influences. There would be a natural inclination to "test" the winner against other strong candidates either as a final step in the decision process or in the opinion. As long as there are only a few applicants, the FCC and the courts can easily compare the "winner" against all the other applicants.

165. Commentators have recognized the possibility that the FCC may labor diligently to write an opinion that rests solidly on public interest grounds. See H. FriendLy, The Federal Administrative Agencies 59-60 (1962) (FCC opinions sometimes include "tortuous argumentation wherein the opinion writer seeks to give the successful applicant a preference under every 'criterion' or at least to minimize its disadvantage"); id. at 63 (changes in policy may be disguised so that "the opinion writers remain free to pull [the prior authorities] out of the drawer whenever the agency wishes to reach a result supportable by the old rule but not the new").

166. The FCC usually simply states the rankings of various applicants under different criteria and then selects a licensee after a sequence of conclusory comparisons between 
Axioms IV and IX could be violated most easily and with the least chance of detection because either axiom may be violated without any conscious falsification on the part of the Commission. The FCC can violate axiom IV without consciously using absolute scales or absolute weights if it uses rough rules of thumb to compare the significance of characteristics under different criteria. Use of rough rules of thumb can violate axiom IV as effectively as use of absolute weights or of an absolute scale. ${ }^{167}$ Moreover, it would be hard to detect a deliberate or inadvertent violation of axiom IV, even if the comparative hearing process did not violate any of the other axioms. ${ }^{168}$ As long as the FCC claims that " $[\mathrm{t}] \mathrm{he}$ weight to be given to each factor is dependent upon the circumstances of each particular case," 160 no rationale need support the use of particular weights in any given case other than talismanic public interest language. As a result, it would be easy to hide absolute weights or absolute scales behind a facade of conclusory statements much like those that presently characterize FCC opinions. Further, the rough rules of thumb might shift over time as the Commission changed its conception of the public interest. The FCC would feel no need to articulate the change since the weights used in any decision could be characterized as unique. ${ }^{170}$ Such circumstances would probably prevent detection of a system of absolute weights. One could not distinguish between the claim that no absolute weights or absolute scales are used and the claim that such weights and scales are used, but the precise weights or scales change over time. ${ }^{171}$

applicants based on performance under all of the criteria. See note 164 supra (citing cases). Since the treatment of the significance of comparative performance under each criterion is conclusory, as long as a candidate is superior under at least one criterion, that candidate can be chosen. In fact, commentators have noted that the comparative hearing process seems to operate without any apparent rules governing the combination of criteria into a choice. See note 171 infra.

167. See pp. 721-22 supra.

168. If some of the other axioms are violated, detection of a violation of axiom IV would be even more difficult. For example, if the FCG violated axiom IX by letting influences not covered by the criteria affect the decision, then decisions might be too haphazard to allow detection of absolute weights or absolute scales.

169. Hearst Radio, Inc., I5 F.C.C. 1149, 1176 (1951). The FCC repeated this assertion after its 1965 policy statement. See p. 736 supra.

170. Although there is a requirement both that changes in policy be articulated and that a reasoned explanation be given for the changes, see p. 738 supra, if the FCC uses different weights in each particular case, therc is no general policy to alter or explain.

171. Commentators have repeatedly noted that the FCC operates with no rules for the combination of criteria into a choice. See, e.g., H. FRIEndey, supra note 165, at 67 (FCC "must develop enough courage to penetrate the fog it has helped create" by revealing clearly what weight newspaper ownership will carry); Botein, Comparative Broadcast Licensing Procedures and the Rule of Law: A Fuller Investigation, 6 GA. L. REv. 743, 752-54 (1972) (FCC comparative hearings operate under vague and contradictory criteria and are inherently subjective). In a statistical analysis of comparative hearings for granting television stations, one study has even shown that qualities that the FCC claims 
If the FCC's MCCP violates axiom IX, then factors not among the criteria claimed to comprise the MCCP may enter into the decision process. In this case, the FCC would have to hide its use of outside factors by not revealing the entire basis for its decision. Axiom IX, however, can also be violated without any intent to deceive on the part of the Commission. The objectives of the decision process may be so illdefined that identical cases are not necessarily decided identically. ${ }^{172}$ A violation of axiom IX arising in this manner would be difficult to detect. Absolutely identical cases will never arise, and it is hard to evaluate the significance of small variations from case to case when the weights that criteria will receive in different cases are as ill-defined as they are at present.

This discussion indicates the futility of attempting to establish definitely, by empirical analysis, which of the nine axioms is violated. The more difficult it is to detect the violation of any particular axiom, the more likely it is that the axiom is, in fact, violated. When detection is easy, appellate review and public criticism will forestall or rapidly correct violations. Conversely, difficult detection may tempt the Commission to commit violations.

\section{General Implications of this Analysis}

\section{The Seriousness of the Problem}

One might suggest that, despite the results derived here, the comparative hearing works well enough to be continued. It is important, however, to recognize the seriousness of the comparative hearing's defects. Any violation of an axiom by the FCC constitutes a violation of a legal standard. In addition, some of the most likely violations are also the most serious. If axiom I is violated, the FCC does not, or cannot, despite its claims, rely entirely on its MCCP to choose a single broad-

are desirable actually have lessened an applicant's chances of being awarded a license. See R. Noll, M. Peck \& J. McGowan, Economic Aspects of Television Regulation 112-14 (1973).

One recent case may indicate some judicial awareness of this problem. See Central Fla. Enterprises, Inc. v. FCC, 4 MEdiA L. ReP. (BNA) 1502, 1510 (D.C. Cir. Sept. 25, 1978), amended, No. 76-1742 (D.C. Cir. Jan. 12, 1979) (renewal hearing) (FCC has not "even vaguely described how it aggregated its findings into the decisive balance," but simply indicated that it relied on " "administrative "feel" " "; "[s] uch intuitional forms of decisionmaking, completely opaque to judicial review, fall somewhere on the distant side of arbitrary").

172. The Commission has only the vague statutory standard of the "public convenience, interest or necessity" as an ultimate guide for its choices. See p. 734 supra; H. FRIENDLY, supra note 165 , at $54-57$ (vagueness of congressional mandate leaves FCC to perform frustrating task with little guidance). 
cast licensee in each case. ${ }^{173}$ If axiom $\mathrm{V}$ is violated, the Commission either cannot draw distinctions based on the statutory public interest standard, or it makes some decisions directly contrary to that standard. ${ }^{174}$ If axiom IV is violated, then the Commission uses a secret system of absolute scales or absolute weights despite claims to the contrary. ${ }^{175}$ If axiom IX is violated, then irrelevant factors are influencing decisions or the choice process is so ill-defined that identical cases may not be decided identically. ${ }^{176}$ Each of these violations contravenes deeply-held tenets of the administrative process: those subject to the process are entitled to be given at least a rudimentary knowledge of its operation, ${ }^{177}$ and agencies gain their power from and must adhere to the statutory purposes specified by the legislative branch. ${ }^{178}$

The possibility theorem's attack upon comparative hearings is bolstered by commentators' criticisms. Three common criticisms of the process are that it fails to implement the policy objectives inherent in the agency's own criteria, ${ }^{179}$ that its extreme vagueness engenders a

173. See p. 739 supra.

174. See pp. 741-42 supra.

175. See pp. 740-41 supra. The secret use of absolute scales or absolute weights may not be deliberate. See p. 747 supra.

176. See pp. 744,748 supra.

177. See p. 738 supra (reasoned decisionmaking requirements). Some commentators have contended that when there is an allocative decision that involves a clash of fundamental values, it may be desirable to allow the clash to be resolved in a way that does not appear to violate either value. Such a result is usually accomplished via "sub. terfuges" that hide the fact that one value will be sacrificed for the sake of another. See note 68 supra. It is doubtful, however, that these commentators would judge that preserving all of the axioms, especially IV and VI, which could be violated without sacrificing the principles of rational decisionmaking, is a vital enough objective to justify subterfuge.

178. In theory, Congress cannot delegate power to agencies unless it does so by legislation whose "explicit or reasonably discernible implicit purposes, and . . . history, taken together" provide "the administrator with sufficiently clear guidance" so that a reviewing court "can 'ascertain whether the will of Congress has been obeyed." McGowan, Congress, Court, and Control of Delegated Power, 77 Colum. L. Rev. 1119, 1127-28 (1977) (footnote omitted). In practice this "delegation doctrine" is never used by federal courts to strike down legislation. Id. at 1127. Judge McGowan, however, has suggested that it might be appropriate to revive the doctrine for cases "in which Congress debates alternative policy choices entirely feasible for it to make, but chooses instead to compromise the matter by delegation in order to get a bill enacted or to avert the assumption of direct responsibility." Id. at $1129-30$ (footnotes omitted). In the Judge's opinion, such cases involve "a subversion of the democratic decisionmaking contemplated by the Constitution, as well as an imposition upon both the administrative process and judicial review." Id. at 1130 (footnote omitted).

179. See note 171 supra; Fisher, The President's Comment, 21 FED. CoM. B.J. 117, 118 (1967) (procedures have "not reflected the only two policy principles [diversification of ownership and integration of management and ownership] of consequence in the broadcast field"); Geller, $A$ Modest Proposal for Modest Reform of the Federal Communications Commission, 63 GEo. L.J. 705, 715-18 (1975) (criteria and standards for combining them often ignored or unsatisfactorily explained away; failure to implement policies inherent in many criteria is evident and there is some evidence that political or other biases dictate some decisions). 
great potential for illegitimate influences, ${ }^{180}$ and that it is too timeconsuming and expensive. ${ }^{181}$ The first criticism is clearly related to possible violations of the axioms. If axiom IX is violated, then either the criteria are applied inconsistently or factors other than the criteria affect decisions. If axiom $I$ or the first part of axiom $V$ are violated, then the decision process does not use the criteria as the sole vehicle for choosing licensees. If the second part of axiom V is violated, the MCCP picks the less desirable of a pair of applicants. If axiom VI is violated, all but one of the criteria are ignored. If axiom VIII is violated, then an applicant who is inferior to another under every criterion may be chosen. If axiom VII is violated, then the agenda as well as the criteria influence the decision. Only a violation of axiom IV might not involve a serious departure from the policies inherent in the criteria, but even if that axiom is violated, continual shifting of the weights, scales, or rough rules of thumb employed can leave the impression that the policies underlying the criteria are not implemented in a consistent manner. ${ }^{182}$

The possibility theorem also helps illuminate the fear that illicit influences might enter into the process. Three of the five axioms most likely to be violated, $\mathrm{I}, \mathrm{V}$, and IX, are axioms that limit the process to a decision based on the criteria. ${ }^{183}$ If the comparative hearing process violates any of these axioms, then it is likely that outside and possibly illicit influences affect the decision process. ${ }^{184}$

Finally, given the nature of the axioms and the fact that one of them must be violated, it is not surprising that the comparative hearing process has turned out to be costly and time-consuming. If no absolute

180. See Geller, supra note 179, at 715-18 (flexibility of process FCC uses in selecting licensees leads to heavy role for preferences of commissioners); Johnson, $A$ New Fidelity to the Regulatory Ideal, 59 GEo. L.J. 869, 883, 885 (1971) (discussing attempts by those regulated by FCC to influence Commission via lobbying and public relations campaigns; "deferred bribe" of future employment with broadcasters may affect decisionmaking by FCC personnel); Levin, Regulatory Efficiency, Reform and the FCC, 50 Geo. L.J. 1, 24-25 (1961) (applicants may attempt to influence FCC through congressional pressure, by approaching commissioners who may be dependent on applicant for future employment, or by making inflated and impossible claims about future performance).

181. See, e.g., Anthony, supra note 70, at 47 (uncertainty in and diversity of issues are primary cause for length and complexity of comparative hearings; lawyers in such situation will quite properly assemble huge record in order not to fail to point out any fact that may help client obtain license-result in many cases is vast amount of irrelevant material in record); Levin, supra note 180 , at $26-29$ (delay and high cost characterize hearings).

182. See p. 747 supra.

183. See pp. 746-47 supra.

184. If influences other than performance under the criteria may be decisive, ap. plicants may attempt to apply political pressure on the FCC or to bribe commissioners by offers of future employment. See note 180 supra. 
scales or absolute weights are used, or if the FCC secretly uses weights or scales that it periodically alters, ${ }^{185}$ applicants in a comparative hearing will have great difficulty in ascertaining what rankings will lead to a license award. As a result, the applicants will be tempted to submit tremendous amounts of detailed evidence in an effort to cover all possibilities. Hearing examiners, afraid of excluding possibly relevant facts, will tend to accept almost all of the evidence submitted and allow applicants to argue the importance of each fact. The elements of cost and delay will be further exacerbated if axioms I, V, or IX are violated, because then applicants can not safely limit themselves to arguing about facts linked to the criteria. ${ }^{186}$ The inability to predict what rankings will lead to a license may tempt applicants to expend resources, not to improve themselves, but to exert political pressure on the FCC or to bribe FCC personnel by offering them future jobs with the applicant. ${ }^{187}$

\section{Implications for Reform Proposals}

In evaluating proposed reforms of the licensing process, a crucial issue is which axiom the FCC should choose to violate, in order to escape from the impossibility of satisfying all of them. ${ }^{188}$ There are two routes that reform might take. First, some reforms retain a rational decisionmaking procedure aimed at choosing applicants who will maximize social objectives. Reforms from this group must satisfy axioms I, III, V, VII, VIII, and IX, which are rationality constraints, ${ }^{189}$ in addition to satisfying the physical constraint inherent in axiom II. Axioms IV and VI can be violated: an absolute weights or absolute scales

185. It is likely that one of these two possibilities holds because there is no apparent set of rules that the FCC relies on to combine criteria into a choice. See note 171 supra.

186. A violation of axiom VI through the adoption of a single criterion choice process would reduce costs if the parties to comparative broadcast hearings knew that such a process was in effect. If the parties knew, however, courts would probably also know and would prevent the use of such a process.

187. See p. 750 \& note 180 stupra.

188. A large body of literature explores the process of deleting or changing public choice axioms in response to the conclusion that a choice process cannot simultaneously satisfy a set of axioms. See, e.g., Mueller, supra note 2, at 419.22; Plott, supra note 107, at 55I-54.

189. If axiom I or VII is violated, the decision process is not based entirely on the criteria meant to govern choices under the process. If axiom III is violated, then some minimally qualified applicants cannot be considered in the choice process despite the fact that they would be chosen if no other applicant were available. If axiom $V$ is violated, then either the process cannot form preferences between applicants on the basis of the criteria that are supposed to govern the process or applicants may be chosen in direct contradiction to the outcome dictated by the criteria. If axiom VIII is violated, then the choice dictated by the criteria that govern the choice process may not be the actual choice. If axiom IX is violated, then the choice process is arbitrary in the sense that different applicants will be chosen in factually identical cases. 
method of combining criteria can be employed or the decision process can be reduced to one that rests on a single criterion. Second, other reforms abandon the rational decisionmaking procedure in favor of a lottery or similar device not requiring evaluation by the FCC. If this path is followed, axiom IX no longer constrains the choice process. $^{190}$ Commentators have offered reform proposals that fit within each of these two groups. The most commonly proposed reforms include, in the first group, an auction, "first come, first served," and absolute weights or scales, and, in the second group, a lottery.

Several commentators have favored or considered use of an auction. ${ }^{191}$ Applicants would be required to possess specified minimal qualifications, and the highest minimally qualified bidder would be awarded the license. Such a procedure employs the single criterion of number of dollars bid, and thus violates axiom VI. "First come, first served," a similar escape from the impossibility result, would award each license to the first minimally qualified applicant to file an application. Although criticized on grounds of general broadcast policy and on the ground that programming regulation would be required, ${ }^{102}$ such a system would avoid the impossibility result by using only the single criterion of application speed. Finally, one commentator has proposed that the licensing process rest in part on an absolute weights

190. The outcome in factually identical cases could be different because evaluation of the facts under a set of criteria would not enter into the decision.

191. Even though they disagree about the desirable degree of continued government regulation of broadcasting, some writers have suggested auctioning rights to broadcast. See Coase, The Federal Communications Commission, 2 J.L. \& ECoN. 1, 23-24, 30-35 (1959) (favoring auctioning rights to broadcast combined with minimal regulation); De Vany, Eckert, Meyers, O'Hara \& Scott, A Property System for Market Allocation of the Electromagnetic Spectrum: A Legal-Economic-Engineering Study, 21 STAN. L. REv. 1499, 1532-33, 1556-59 (1969) (advocating use of auction at least on experimental basis to allocate portions of electromagnetic spectrum); Levin, supra note 180, at 22-23, 29-37 (favoring auction as possibility in setting of continued government regulation and control). Other commentators have considered an auction procedure, but have rejected it for various reasons. See Anthony, supra note 70, at 99-102 (auction would be quick, cheap, and conclusive but would result in abandoning public interest considerations in allocating broadcast rights and would put premium on financial resources); Botein, supra note 171, at 759.61 (auction, although "administratively feasible and economically valid" would "abandon any attempt at reaching a reasoned decision" based on public interest); Grunewald, Should the Comparative Hearing Process Be Retained in Television Licensing? 13 AM. U.L. REv. 164, 167-69 (1964) (auction would eliminate delays and possible improprieties in present allocation process, but would lead to excessive commercialism and possibly to concentration of ownership in hands of wealthy).

192. See Anthony, supra note 70, at 102-04 (first come, first served system would ignore public interest considerations and would unfairly penalize careful preparation of applications; also, hard questions as to completeness of applications might arise); Grunewald, supra note 191, at $168-69$ (use of first come, first served system would require programming regulation by $\mathrm{FCC})$. 
and absolute scales approach. ${ }^{193}$ Insofar as the process relied on that approach, it would avoid the impossibility result by violating axiom IV.

Some commentators have considered use of a lottery to choose broadcast licensees from the pool of minimally qualified applicants. ${ }^{194}$ The adoption of a lottery would mean the abandonment of rational decisionmaking in favor of allowing chance to dictate the result in any given case. ${ }^{195}$ As a consequence, the process would not have to conform to axiom IX.

Many reform proposals, although attractive on the surface, will be ineffective unless combined with measures that release the FCC from one of the axioms. For example, at least one commentator has suggested that granting longer tenure for commissioners and taking other steps

193. See Anthony, supra note 70, at 64-66. Anthony suggests that the FCC take four steps to set up "a system of standards and priorities for choosing among mutually ex. clusive applicants in broadcast licensing cases." Id. at 64. First, criteria must be selected to evaluate applicants. Id. Second, the FCC should formulate "standards for awarding applicants fixed credits under each of those" criteria. Id. Third, the Commission should set up a "schedule of priority categories to rank the applicants on the basis of the credits they earn." Id. In doing so, a "weighted point system may be helpful." Id. Finally, the FCC should award each license to the applicant with the greatest number of total credits with ties to be broken by lot. Id.

After setting out the four steps, Anthony provides a specific illustration of his type of system. Id. at 64-65. In the illustration, diversification of control of mass media and past broadcast record are the only criteria. Under the diversification criterion, the FCC awards an applicant three points if the applicant has no substantial media interests, two points for no substantial interest in nearby or national media, and zero points otherwise. Under the past-broadcast-record criterion, an applicant earns four points for an outstanding record, one point for a satisfactory record, and zero points otherwise. Each applicant's points are totaled, and the applicant with the most points gets the license.

Such a system would violate axiom IV insofar as it relied upon an absolute-weights system as in the illustration. In practice, a system like Anthony's proposal might function as a lottery. Because broadcast rights are valuable, it would seem likely that several ap. plicants, each with outstanding broadcast records and no substantial media interests, would apply for each license. The highest level under each criterion would in effect become a minimum standard, and the FCC would use a lottery as the core of its choice process.

191. See id. at 102 (lottery offers all benefits of auction-“"speed, economy, objectivity, and conclusiveness"; lottery avoids defects of auction except for lack of explicit public interest considerations in choice of licensee); Botein, supra note 171, at 758-59 (lottery might reduce administrative costs and potential corruption in present system but result could be that "by concentrating on threshold qualifications . . . a lottery would just shift the procedural locus of the comparative hearing's deficiencies" without any reduction in either costs or potential corruption); Grunewald, supra note 191, at 169 (Iottery system could be used, thereby cutting costs and political influences on choices, but such system might require programming regulation by FCC).

Judge Leventhal, in discussing reform of the comparative hearing, suggested that "[p]erhaps a lottery could be used, for luck is not an inadmissible means of deciding the undecidable." Star Television, Inc. v. FCC, 416 F.2d 1086, 1095 (D.C. Cir.), cert. denied, 396 U.S. 888 (1969) (Leventhal, J., dissenting).

195. One could visualize a lottery as a single criterion choice process that violates axiom VI. The single criterion would be the outcome of the draw. Chance, however, seems to have little to do with the public interest goal that underlies the comparative hearing process. 
to attract more highly qualified commissioners might alleviate the defects of the comparative hearing process. ${ }^{190}$ An FCC composed of commissioners "dedicated to the public interest would be effective despite structural deficiencies, possibly inconsistent duties, and vaguely defined legislative standards." 197 A proposal of this sort is rooted in a deeper conception of the "New Deal" administrative agency. Well-trained administrators will develop "expertise" in their agency's subject area. When faced with a problem, these expert administrators will naturally understand all of the complexities presented and then somehow will combine all of the considerations into the "best" resolution of the problem. ${ }^{198}$ Yet, regardless of their quality or expertise, decisionmakers who conduct the current FCC comparative hearing process must act in a way that offends at least one implicit or explicit legal constraint. Improving personnel will be futile since the process itself is internally inconsistent.

Other reform proposals are similarly flawed. A former FCC hearing examiner has urged that if the parties to each hearing proceeded with fuller, clearer, and more concise reasoning, then "it may be fairly assumed that the decisions, both initial and final, would likewise take on a desired quality of logic and consistency." 199 Judge Friendly suggested in 1962 that the criteria in the FCC's MCCP be given better definition by means of policy statements or rulemaking. ${ }^{200}$ The FCC issued its 1965 policy statement "to serve the purpose of clarity and consistency of decision, and the further purpose of eliminating from the hearing process time-consuming elements not substantially related to the public interest." 201 In that policy statement, the FCC reduced the number of criteria to be considered and refined the elements to be considered under each criterion. ${ }^{202}$ One commentator has urged direct

196. See Geller, supra note 179 , at $720-24$ (in order to secure higher quality commissioners, they should have 15 -year terms with no reappointment possible and should be barred from employment in communications field for five years after FCC service).

197. Id. at 720-21.

198. See Freedman, Crisis and Legitimacy in the Administrative Process, 27 STAN. L. REv. 1041, 1056-60 (1975) (criticizing and tracing development of expertise rationale).

199. Irion, FCC Criteria for Evaluating Competing Applicants, 43 MrNN. L. Rev. 479, 498 (1959).

200. See H. FriendLy, supra note 165, at 67-69; id. at 69 (policy statement with respect to diversification criterion "would promote administrative consistency and intelligibility, and also facilitate congressional action if Congress desired to act").

201. 1965 Policy Statement, supra note 82 , at 394.

202. Prior to the policy statement, the FCC commonly compared applicants under a large number of criteria including local ownership, integration of ownership and management, participation in civic activity, diversification of background of stockholders, length of total past broadcast experience, record of past broadcast experience (including sense of public service responsibility), proposed program policies, proposed staff and technical facilities, and diversification of ownership of mass media. See Television Inquiry: Hearings Pursuant to S. Res. 13 \& 163 Before the Senate Comm. on Interstate and Foreign 
steps to increase the efficiency of the hearing process: reducing the classes of relevant evidence, limiting the hearings in time, and limiting the amount of written evidence that will be considered. ${ }^{203}$ Steps like increasing the level of advocacy, refining the criteria, and attempting to make hearings more efficient all stop short of remedying the basic inconsistencies of the present comparative hearing process. More effective advocates, like more effective commissioners, cannot cure defects that arise from the process itself. The refinement of the criteria in the 1965 policy statement left the structure of the hearing process fundamentally unchanged.204 Attempts to improve the efficiency of the system by limiting evidence that can be presented do not address the basic problem: counsel will tend to submit a great deal of evidence when faced with a process that allocates extremely valuable rights but does not give a clear indication about the basis upon which decisions will rest. 205

\section{Conclusions}

Public choice theory can provide insight into administrative agency decision processes. After expressing the physical and legal constraints

Commerce, 84th Cong., 2d Sess. 979 (1956) (letter from George C. McConnaughey, FCC Chairman); Irion, supra note 199 , at 481 . The 1965 policy statement reduced the number of commonly used criteria to three or four. See pp. 734-36 supra. Only a reduction to one criterion, however, would have ensured that the FCC could escape from the serious consequences of the fact that no MCCP can simultaneously satisfy the nine axioms.

203. See Grunewald, supra note 191, at 178-80 (favoring expediting hearings by FCC limitations on permissible evidence, on total time of hearing process, and on amount of written material submitted; also favoring deletion of such unnecessary considerations as staffing and signal strength).

204. WHDH, Inc., 22 F.C.C. 767 (1957), illustrates the ineffectiveness of the 1965 policy statement. In 1954, the FCC began comparative hearings to grant the initial broadcast license for television channel five in Boston to one of four minimally qualified applicants. After weighing and balancing rankings under 13 different criteria, see id. at 859.81, the Commission selected a winner, WHDH. The choice process was slow, turbid, and unpredictable. Because the Commission later discovered that representatives of WHDH had attempted to influence the FCC Chairman improperly while the comparative hearings were in progress, WHDH's grant was voided. See WHDH, Inc., 29 F.C.C. 204, 212-13 (1960). Three competing applicants challenged WHDH at renewal time and, due to various delays, the Commission's final decision was not rendered until 1969. WHDH, Inc., 16 F.C.C.2d 1 (1969). Because the FCC treated the renewal hearing as if it were an initial licensing hearing under the 1965 policy statement, see id. at 7-8, a scholar can compare the initial disposition of channel five before and after the policy statement. This comparison shows that the 1969 decision was only slightly more acceptable than the 1957 decision. When the 1969 hearings compared the four applicants under only four categories, see id. at 10-17, one applicant ranked no lower than any other applicant under every criterion and thus was awarded the license. Unfortunately, the relationship between the evidence and the rankings was not obvious-the hearing examiner had chosen a different licensee on the same facts. $I d$. at $8-10,19$. If the ultimate winner had not been preferred under every criterion, the Commission would have had to engage in the same unsatisfactory weighing and balancing process that characterized pre-1965 decisions. In addition, of course, the decision process remained very slow.

205. See pp. 750.51 \& note 181 supra. 
on an agency as axioms, one can test a decision process for internal consistency. A finding of inconsistency is valuable for two reasons. First, forcing litigants and public servants to operate within an internally inconsistent system has heavy costs. Even the most able and idealistic administrators will be frustrated when their best efforts must result in a violation of a principle that they accept or are constrained to obey. Resources are wasted and risks of corruption or illicit influence arise when lawyers and parties have to work within an inconsistent system. If the faulty system is an adjudicative mechanism, its continued failure to live up to the constraints placed on it may undermine public confidence not only in the mechanism, but also in law and government themselves. In addition to helping to detect internal inconsistency in agency decision processes, public choice theory also helps to separate useful reform efforts from those that are doomed to failure. A successful reform effort must lead to a relaxation of one of the axiomatic constraints that leads to inconsistency. Otherwise, even well-intentioned proposals will be ineffective.

\section{The Use of Internally Inconsistent Multicriteria Choice Pro- cesses by Courts}

Like administrative agencies, courts sometimes use MCCPs. These MCCPs may be required by statute ${ }^{206}$ or they may be created inde-

206. Federal law dealing with bank mergers, for example, establishes an MCCP for determining the legality of anticompetitive mergers. The statute provides that the responsible agency shall not approve a bank merger that will substantially reduce competition or cause a restraint of trade "unless it finds that the anticompetitive effects of the proposed transaction are clearly outweighed in the public interest by the probable effect of the transaction in meeting the convenience and needs of the community to be served." 12 U.S.C. $\$ 1828(\mathrm{C})(5)(B)(1976)$. The section further provides that "[i]n every case, the responsible agency shall take into consideration the financial and managerial resources and future prospects of the existing and proposed institutions, and the convenience and needs of the community to be served." Id. The statute therefore provides several criteria under which the agency is to reach a decision.

In United States v. First City Nat'l Bank, 386 U.S. 361 (1967), the Supreme Court considered the role of courts in reviewing bank merger decisions by the responsible agency. Id. at 367-70. Federal law provides that "the standards applied by the court" in such cases "shall be identical with" those that the responsible agency must apply. 12 U.S.C. $\S 1828(\mathrm{c})(7)(\mathrm{B})$ (1976). In addition, I2 U.S.C. $\$ 1828(\mathrm{c})(7)(\mathrm{A})(1976)$ requires the court to "review de novo the issue presented" in bank merger cases. In First City National Bank the Court held that under these provisions courts should make an "independent determination of the issues," which need not give any weight to the agency determination. 386 U.S. at 368 . As a result, it is " $[$ t]he task of the district courts . . . to inquire de novo into the validity of a bank merger" to determine "whether the merger offended the antitrust laws and .... if it did, whether the banks had established that the merger was nonetheless justified by the convenience and needs of the community to be served." United States v. Third Nat'l Bank, 390 U.S. 171, 178 (1968). Thus, courts must evaluate the convenience and needs defense under the statutory MCCP. 
pendently by the courts themselves. ${ }^{207}$ There are a number of ways in which one might apply public choice analyses to judicial decisionmaking. ${ }^{208}$ This section focuses on the task of analyzing judicial choice processes using the possibility theorem developed previously. ${ }^{200}$

Violations of some of the axioms by courts would be highly significant. For example, if it were known that all the axioms but axiom $\mathrm{V}$ were satisfied, then either the judiciary would not be able to distinguish between alternatives on the basis of the criteria it claims to use or there would be a possibility that the judiciary was choosing inferior alternatives. ${ }^{210}$ Either situation would be extremely serious for an institution that derives its legitimacy in a democracy from a reliance on principled decisionmaking. ${ }^{211}$ It is generally much more difficult, however, to apply the possibility theorem to the judicial process. Because of the nature of the process, courts reveal less of their decisionmaking process than do administrative agencies. ${ }^{212}$ Thus, it may be quite dif-

207. One example is the way in which courts decide the state of corporate citizenship in diversity jurisdiction cases. Under the Constitution, "[ $t$ ]he judicial Power shall extend ... to Controversies . . . between Citizens of different States." U.S. ConsT. art. III, § 2. If any civil action over which the federal courts have original jurisdiction is filed in state courts, it "may be removed by the defendant . . . to the district court of the United States." 28 U.S.C. $\S 1441$ (a) (1976). When a defendant corporation seeks to remove a state court action under diversity of citizenship, the corporation's state "citizenship" is a crucial issue. Because federal statutes equate citizenship with the corporation's "principal place of business," id. $\S 1332$ (c), courts must choose one principal state of business from a set of mutually exclusive alternatives. Courts appear to use an MCCP to make this determination. See Kelly v. United States Steel Corp., 284 F.2d 850, 854 (3d Cir. 1960) (ranking states and deciding principal place of business under criteria that include location of administrative officers, location of corporate employees, location of tangible property, and location of productive capacity).

208. For example, Levine \& Plott, supra note 5 , at $563,592-96$, suggests that models of voting behavior can be used to illuminate the agenda influences inherent in the rendering of special verdicts by courts.

209. The axioms used here are only one of many possible sets of axioms. Because this set includes axiom II-which requires that there be at least three potential choices-it can only produce interesting conclusions concerning judicial decisions involving at least three possible outcomes. Compare note 206 supra (bank merger law allows only two outcomes) with note 218 infra (many possible outcomes in procedural due process cases).

210. See pp. 722-23 supra (stating and discussing axiom V).

211. Administrative agencies are subject to the legal requirement of "reasoned decisionmaking." See p. 738 supra. Although courts are not subject to a similar legal requirement, and although for the highest level of appellate courts there is no formal institution to oversee the quality of decisionmaking, many scholars have argued that courts derive their legitimacy in a democratic society from basing decisions upon principle. See, e.g., A. Bicked, The Least Dangerous Branch 205-06, 238-40 (1962); Wechsler, Toward Neutral Principles of Constitutional Law, 73 Harv. L. REv. 1, 15, 19 (1959) (judicial judgments must not be ad hoc and merely political, but based on principles that both transcend given case and require particular result).

212. A court is limited to deciding the cases before it. Although it can enunciate general standards and principles in any given case, it cannot comprehensively detail its decisionmaking process in a particular area of law by a device like the FCC's 1965 policy statement. See, e.g., Flast v. Cohen, 392 U.S. 83, 94-97 (1968) (dictum) (constitutional 
ficult to discern from judicial opinions whether particular axioms are satisfied or, indeed, whether an MCCP is used at all. Moreover, even when the possibility theorem can be applied, violations of some of the axioms have different implications for courts than for administrative agencies.

\section{A. Difficulties in Deciding Whether an MCCP is Used and Whether the Nine Axioms Apply-An Illustrative Example}

This discussion uses procedural due process cases to illustrate the difficulties inherent in ascertaining whether courts use an MCCP and whether certain of the nine axioms apply.

\section{Procedural Due Process-Is an MCCP Used?}

Currently, courts examine three criteria to determine what procedures are constitutionally required before the government takes an action harming a person or denying him a valuable benefit: ${ }^{213}$ the private interest affected, the risk of error, and the government's interests. ${ }^{214}$ This test was set out by the Supreme Court in Mathews $v$. Eldridge, ${ }^{215}$ and has been repeatedly used by the Court in procedural due process cases. ${ }^{216}$

The definition of an MCCP includes three aspects: specifying a finite number of criteria for evaluating alternatives, ranking the al-

restriction of federal jurisdiction to "cases" and "controversies" bars federal judiciary from issuing advisory opinions); Muskrat v. United States, 219 U.S. 346, 361 (1911) (federal judicial power is limited to "the right to determine actual controversies arising between adverse litigants"). Furthermore, an administrative agency often deals with a single problem over a long period of time while courts spend much of their time dealing with new, unresolved problems. See pp. 763-64 infra (litigators will not tend to raise issues that are resolved and courts can dispose of such issues summarily when raised). Even though a court can enunciate general principles in a particular case, it is often reluctant to do so until there is a body of related case law. See Friendly, "Some Kind of Hearing", 123 U. PA. L. Rev. 1267, 1301-02 (1975) (comprehensive prescription of procedures required by due process in certain types of cases amounts to unwise judicial legislation; it is best to allow slow evolution of requirements through case law). By that time, however, a court may be able to impose a clear solution; it may be able to establish an MCCP with clearly established weights for various criteria.

213. The determination of the procedures that are necessary follows the determination that a plaintiff has an interest in "life, liberty or property" that falls within the due process clause. U.S. ConsT. amend. XIV. If he does not have such an interest, then the government need not make available any particular procedure. See Note, Specifying the Procedures Required by Due Process: Toward Limits on the Use of Interest Balancing, 88 Harv. L. REv. 1510, 1510 (1975).

214. See Mathews v. Eldridge, 424 U.S. 319 , $334-35$ (1976).

215. Id.

216. See, e.g., Dixon v. Love, 431 U.S. $105,112-15$ (1977) (procedures required before suspension of driver's license); Ingraham v. Wright, 430 U.S. 651, $674-82$ (1977) (procedures provided by public school before corporal punishment permitted). 
ternatives under each criterion, and combining the rankings into a choice. ${ }^{217}$ In a procedural due process case, it is plausible to assume that alternative procedures are ranked by judges under each of the three Mathews criteria. At least in some cases, however, a court will be faced with a large number of possible procedures that are minimally acceptable. ${ }^{218}$ It may be nearly impossible to rank all of the possibilities under each criterion. If courts use an MCCP in such a context, they must do so by limiting consideration to a few candidates. ${ }^{219} \mathrm{But}$, if the initial winnowing process is too restrictive, only one candidate will remain and it will not be necessary to apply an MCCP. Thus, the argument that courts rank alternatives to decide what process is due depends on rather delicate assumptions about the existence and strength of this winnowing process. 220

Failure to rank alternatives under the criteria is only one way in which a judicial decisionmaking process can fail to conform to the definition of an MCCP. The other major way is failure to use criteria at all. This discussion is limited, however, to situations in which courts explicitly employ a set of criteria to evaluate alternatives.

\section{Difficulties in Determining Whether Axioms I and II Apply}

A threshold issue that arises in applying the possibility theorem to a judicial MCCP is whether there are at least three alternatives, each of which would be chosen if no other alternatives were available. If not, then axiom II, which is a merely technical requirement, will not be satisfied. ${ }^{221}$ As a result, one will not be able to say on the basis of the possibility theorem that one of the more interesting axioms must be violated. Many cases have only two outcomes; sometimes, for example, the question may be only whether or not a particular procedure is adequate.

217. See p. 719 supra.

218. There may be many possible combinations of procedural elements that could be required in a given case. See Friendly, supra note 212, at $1279-95$ (listing 11 elements). Within some of the elements there may be many gradations. Thus, even when only a few procedural elements are under consideration, there may still be many possible combinations.

219. In FCC comparative hearings, the number of candidates is limited both by the number that apply and by the FCC's own initial winnowing process, which excludes candidates that do not possess certain minimal qualifications. See pp. 733-34 supra.

220. In FCC comparative hearings, the number of candidates that must be considered is limited by the number of applicants. A parallel limitation in procedural due process cases-might be that courts will only consider the parties' own proposed candidates for a minimally required set of procedures. Placing such attention on issues raised by the parties, however, could lead to a "yes-no" type of decision with respect to each procedural element put at issue by the parties. Such a series of decisions would violate axiom II. See pp. 760-61 infra.

221. See p. 721 supra (stating and discussing axiom II). 
For axiom II to be satisfied in the procedural due process cases, the decisionmaking process must go beyond a mere "yes-no" determination of whether particular procedures meet minimal constitutional standards. In order to avoid the problem, it is necessary to make assumptions about the hidden mechanics of judicial decisionmaking. One might assume that courts determine what minimal process is due, after considering many possible candidates, before they compare the actual process afforded with what is due. This assumption would avoid the threshold problem of axiom II.

It is difficult to tell from the case law whether the assumption holds. When existing procedures are found to be adequate, there is no reason to specify the minimal requirements or, in some cases, even to consider them. In practice, courts usually do not specify the constitutional minimum in such cases. ${ }^{222}$ However, when courts find existing procedures inadequate, they usually do set out a minimal set of required procedures. ${ }^{23}$ Yet even when they do so, courts may limit themselves to a series of "yes-no" decisions about the need for particular procedural elements. Commentators are sharply divided about whether courts should be comprehensive in specifying what procedure is required.24 If no comprehensive specification is provided, decisionmaking by a series of "yes-no" determinations with respect to each procedural element sought by a party would seem at least as likely as decisionmaking that first defined, in a single step, a comprehensive, minimally required process. ${ }^{225}$ A series of "yes-no" determinations would constitute a set

222. See, e.g., Smith v. Organization of Foster Families, 431 U.S. 816, 855-56 (1977) (finding procedures adequate for transferring foster child to new foster parents); Ingraham v. Wright, 430 U.S. 651, 674-82 (1977) (finding procedures preceding administration of corporal punishment in public school adequate). But see Board of Curators v. Horowitz, 98 S. Ct. 948, 959-62 (1978) (Marshall, J., concurring and dissenting) (attacking majority dictum that procedural due process would have been satisfied by less procedural protection than provided; Mathews test mandated all procedural protection actually provided).

223. See, e.g., Goss v. Lopez, 419 U.S. 565, 577-84 (1975) (requiring notice and informal hearing before short suspension from public school); Goldberg v. Kelly, 397 U.S. 254, 266-71 (1970) (requiring extensive procedural protection before deprivation of welfarc payments).

224. Compare Friendly, supra note 212, at 1301-02 (comprehensive prescription of procedures required amounts to unwise judicial legislation; it is best to allow slow evolution of requirements through case law) with Note, supra note 213, at 1520-21 (to avoid uncertainty, court should always articulate set of procedures to govern not only "case before it" but also "broad range of similar cases").

225. In at least one recent opinion, the Supreme Court undertakes a series of "yes-no" determinations with respect to procedural elements that could be required. See Smith v. Organization of Foster Families, 431 U.S. 816, 850-55 (1977). It is unclear, however, whether this series of arguments represents judicial thought processes. In addition, even if the Smith case was decided by a series of "yes-no" determinations, it may be that other cases are decided by a single-step determination of a comprehensive, minimally required set of procedures. 
of decisions, each of which violated axiom II. In any event, procedural due process opinions do not provide enough insight into the decisionmaking processes of judges to determine whether or not axiom II applies.

A related problem is that there may be no single minimally required set of procedural rights. Some procedural elements may be traded off against others to yield equivalent packages of rights. For indigent plaintiffs in welfare or disability cases whose benefits have been temporarily suspended pending pursuit of formal remedies, for example, the right to counsel without the right to confront adverse witnesses may be roughly equivalent to the right to confront witnesses without any right to counsel. If there are groups of equivalent packages of procedural rights, axiom I's requirement that the MCCP choose one alternative may be violated.20

One might assume that judges merely arrive at a class of equivalent procedures, but there is no support for this assumption in actual opinions. Indeed, in many cases, courts have specified a single procedural package as the constitutional minimum. ${ }^{20}$ It seems more likely that judges see their task as one of discovering such a single minimum procedure. But there remains a significant possibility that their decisionmaking violates axiom I because they could easily choose any of several constitutionally equivalent outcomes. ${ }^{228}$

\section{Applicability of Axioms III-IX}

Axioms III, V, VII, VIII, and IX seem to be desirable traits of the judicial process: courts should be able to consider any potential alternative; they should be able to determine whether one alternative is more desirable, less desirable, or equally desirable to another; they should choose a more desirable alternative over one that is less desirable; the order or "agenda" in which alternatives are considered should

226. Perhaps with this problem in mind. Judge Friendly has produced a list of elements of procedural protection in decreasing order of priority. See Friendly, supra note 212, at 1278-95. Judge Friendly's purpose in producing such a list, as well as a corresponding list ranking the severity of various government actions, was that such lists "may help to produce more principled and predictable decisions" than does the bare requirement that private and government interests be balanced against each other. Id. at 1278. But Friendly also observed that some protections can be traded off against others to obtain a similar amount of overall protection. See id. at 1279 ("the elements of a fair hearing should not be considered separately; if an agency chooses to go further than is constitutionally demanded with respect to one item, this may afford good reason for diminishing or even eliminating another").

227. See note 223 supra (citing cases).

228. Axiom I, like axiom II, is a technical axiom. Violation of axiom I prevents a demonstration that, on the basis of the possibility theorem, an MCCP violates at least one of the more interesting axioms. See p. 759 supra. 
not affect the outcome; an alternative should not be chosen if there is another one that is superior under every criterion; and "irrelevant" criteria should not affect the choice. ${ }^{229}$ Although these axioms cannot be said to be legal constraints analogous to the requirement of "reasoned decisionmaking" that is imposed on administrative agencies, ${ }^{230}$ courts derive their legitimacy in a democracy from grounding their decisions on principle. ${ }^{231}$ It is therefore reasonable to view axioms III, V, VII, VIII, and IX as constraints on any judicial MCCP.

In the procedural due process cases, there is evidence that axioms IV and VI apply. Both the Supreme Court and commentators have indicated that no one criterion is so overwhelmingly important that it would determine the outcome in every case, ${ }^{232}$ so axiom VI appears to be satisfied. In fact, reform proposals often focus on changing from an MCCP to a single criterion choice process even if the single criterion itself is somewhat ill-defined. ${ }^{233}$ Commentators have also noted that the process of "balancing" the criteria seems to be inherently subjective and that the criteria themselves seem to be incommensurable. ${ }^{234}$ Thus, axiom IV appears to be satisfied.

\section{B. The Implications of Judicial Violation of Some of the Axioms}

Violation of at least two of the axioms might be acceptable in a judicial setting. One might have no objection to a court decision that

229. See pp. 721-24 supra (stating and explaining axioms III, V, VII, VIII, and IX).

230. See pp. 739-44 supra (all nine axioms apply to FCC comparative hearings as physical constraints, explicit legal constraints, or implicit legal constraints).

231. See note 211 supra.

232. See, e.g., Mathews v. Eldridge, 424 U.S. 319, 348 (1976) (government interest in minimizing fiscal and administrative burdens on agencies "is a factor that must be weighed" but not "a controlling weight" by itself); Lawrence, $A$ Restatement of the Roth-Fuentes Analysis of Procedural Due Process, 11 GA. L. REv. 477, 502-04 (1977) (Mathews downplayed but did not eliminate government interest as factor and shifted greater emphasis to individual interest).

233. See, e.g., Lawrence, supra note 232, at 507 (proposing that single test of "fairness" to private individuals affected by government action replace present MCCP in determination of form of hearing required by procedural due process); Note, supra note 213, at 1539-42 (single concept of procedural fairness and decency should govern decision as to what process is due rather than group of factors under interest-balancing test).

234. See, e.g., Friendly, supra note 212 , at 1278 (test in procedural due process cases consisting of balancing government interests against individual interests is "uncertain and subjective"); Note, supra note 213, at $1519-20$ ("[n]o scale has been calibrated" that permits courts and administrators "to sensitively and predictably measure either the relative severity of deprivations inflicted upon individuals or the relative importance of gorernmental interests in summary action" and even if weights of government interest and private interest "can somehow be accurately measured in isolation from [each] other," there is "no method" by which they could "be compared"; result of having to compare incommensurables is that it is "unpredictable what procedures are required by due process in particular cases"). 
violated axiom IV by announcing openly an absolute scale for combining various criteria, or violated axiom VI by announcing a singlecriterion test. In addition, although a secret violation of axiom VI appears unacceptable in the judicial context, there may be situations in which a court's covert violation of the axiom, unlike a similar action by an administrative agency, would not be totally unreasonable.

Such a secret violation of axiom IV might be only mildly objectionable when a court faces a complex issue. In such a case, there may be some agreement about the factors that should be considered in deciding the issue, but there may not be enough knowledge or agreement to establish a wise, comprehensive, and systematic solution that will govern future cases. It would then be understandable for a court to enunciate decision criteria without announcing any absolute weights or scales for combining rankings under the criteria. ${ }^{235}$ By announcing the relevant criteria, the court can encourage counsel to concentrate on the appropriate facts in future cases, while, at the same time, avoiding problems that might arise from the premature creation of rules for combining the various criteria into a choice. Later repudiation of prematurely fixed rules would weaken the reputation of the judiciary as a principled, nonlegislative decisionmaking institution ${ }^{236}$ and would harm those who had relied on the previous rules. ${ }^{237}$

The policy formulation situation just described can occur in an administrative agency as well as in a judicial setting. Some agencies go through a period when they learn how to ascertain what policies and decisions are in the public interest. ${ }^{238}$ That period, however, is meant to be of limited duration, and agencies that have been addressing the same problems for decades can be expected to use processes that violate

235. Many scholars and judges agree that a court should not lay down general rules or guidelines when these are not necessary to decide the case before the court. See, e.g., Friendly, supra note 212, at 1301-02 (courts perceive case at hand but not total spectrum of cases that could arise; general rules unnecessarily established by court to decide case may have unintended and undesirable consequences); $c f$. A. BICKEL, supra note 211, at 23840 (legitimacy of Supreme Court rests on ability of Court to make principled decisions that command widespread acceptance; "[ $t]$ he first wisdom" is to defer decision until Court has enough experience to render judgment that will command such acceptance).

236. See notes 211,212 \& 235 supra.

Prolonged operation without the formulation of general rules may also weaken respect for the judiciary. But, in some cases, the premature imposition of rules may be even more detrimental.

237. When an area of law is unsettled and courts are not using even unannounced absolute weights or scales, another type of violation may occur. If one views the principles of res judicata and stare decisis as constraining an MCCP to be consistent over time, then axiom IX must apply to cases that are separated in time. Yet, if the rules for combining outcomes under different criteria are in flux, it may be that there is no guarantee that the same case will be decided the same way on two different occasions.

238. See H. FrIendLY, supra note 165, at 12-14; Freedman, supra note 198, at 1072. 
axiom IV only in a principled and explicit manner, if at all. ${ }^{239}$ On the other hand, courts are constantly required to spend a great deal of time on new, unresolved problems. Litigants will tend not to raise issues that are already clearly resolved, and courts can deal with such issues by summary references to precedent or statute when they do arise. Policy formulation situations can thus be expected to be quite common for courts and somewhat less common for mature administrative agencies.

\section{Conclusion}

Public choice theory can be used to probe the mechanics of adjudication, as well as to analyze voting. The theorem developed here is most usefully applied to tribunals, like administrative agencies, that deal with the same problem continually and are subject to the requirement that their controlling principles of decision be both explicit and reasonable. Although public choice theory cannot eliminate the need to make vexing allocative decisions, such as deciding who shall be admitted to medical school or who shall be given broadcasting licenses, it can point the way toward reforms of our decisionmaking processes that will make those choices more rational and consistent.

239. See In re Formulation of Policies Relating to the Broadcast Renewal Applicant, Stemming from the Comparative Hearing Process, 66 F.C.C.2d 419 (1977) (discussing possibility of using quantitative guidelines in comparative hearings); H. FriendLy, supra note 165 , at 14 (when initial standard is general so that agency can set policy on basis of experience, "it is imperative that steps be taken over the years to define and clarify it"; process of definition and clarification should be "carried to the point of affording a fair degree of predictability of decision in the great majority of cases and of intelligibility in all'). 
Appendix A: Overview of the Proof of Internal Inconsistency and its Relation to Previous Work in Public Choice Theory ${ }^{240}$

Arrow's general possibility theorem ${ }^{241}$ demonstrates that individual preferences cannot be combined to choose a social policy if the choice process must meet certain conditions. The proof that an MCCP cannot simultaneously conform to the nine axioms presented in the text ${ }^{242}$ relies, ultimately, on Arrow's theorem. That theorem assumes that each individual's preferences form an "ordering." An ordering is a relation between alternatives that is "complete," "transitive," and "reflexive."243 "Complete" means that the relation can compare any two alternatives and indicate that one is preferred to another or that there is indifference between them. Completeness is, by definition, a feature of an MCCP because such a process "ranks" the alternatives under each criterion. ${ }^{244}$

An ordering is transitive if the following is true for rankings under a given criterion: where alternative $A$ is at least as good as alternative $B$, and alternative $B$ is at least as good as alternative $C$, alternative $A$ is at least as good as alternative $\mathrm{C}$. This property also follows from the assumption that in an MCCP alternatives are ranked under each criterion. For example, if $A$ is ranked third and therefore is preferred to $B$, who is ranked fifth, and $B$ is preferred to $G$, who is ranked sixth, then $A$ is preferred to $C$. Setting up a ranking under each criterion precludes the possibility of intransitivity under any given criterion. ${ }^{245}$

Finally, a relation is reflexive if it applies when an alternative is considered against itself. For example, if the relation were "at least as good as," then it would be reflexive since an alternative is at least as good as itself under any criterion. Since the analysis has not ruled out ties between alternatives under any given criterion, the relation under consideration must be of the form "is at least as good as" in order to satisfy the reflexivity condition. ${ }^{246}$

240. This appendix links the technical demonstration that the nine axioms cannot simultaneously apply to an MCCP to previous results in public choice theory. The appendix is meant both for the general reader who wishes to know what that link is and for the reader who desires to have a "roadmap" to the proofs in Appendix C.

241. The original version of the theorem and its original proof can be found in $K$. Arrow, supra note 1, at 46.60. A version of the theorem and its proof that is accessible to the general reader appears in A. SEN, supra note 3 , at 37-46.

242. See pp. 720-25 supra.

243. The term "ordering" is not always used to describe a relation that has the three qualities of completeness, transitivity, and reflexivity. See A. SEN, supra note 3, at 9. Those three qualities, however, are assumed to be qualities of the individual preferences considered in the general possibility theorem. See id. at 37.

244. See p. 719 supra.

245. Even though rankings under each criterion are transitive, the overall choice process may not be. For example, in the choice process discussed at pp. 723-24 supra, there are rankings and therefore transitivity under each criterion, but the choice process as a whole is not transitive. Although $\mathbf{A}$ is preferred to $\mathbf{B}$ and $\mathbf{B}$ is preferred to $\mathbf{C}, \mathbf{C}$ is preferred to A. See id.

246. The relation "is at least as good as" still permits one to form a strict ranking. If the relation holds as to $A$ against $B$ but not as to $B$ against $A$, then $A$ is strictly preferred to $B$ since $A$ is at least as good as $B$ but $B$ is not at least as good as $A$. 
In addition to these three conditions on the rankings under the criteria, Arrow's general possibility theorem imposes four major conditions on a choice process. First, the choice process must be able to operate for any particular ordering of the alternatives under the criteria. ${ }^{247}$ This condition is reflected in axiom III. ${ }^{248}$ If a potential candidate with any conceivable set of characteristics can be considered in the choice process, then the choice process must be able to operate for any conceivable set of rankings that could arise. Second, the choice process must conform to the "weak Pareto principle."249 This principle requires that if one alternative is preferred to a second one under every criterion, then the first alternative must be preferred in the choice process. This principle is equivalent to axiom VIII, which states that an alternative will not be chosen when there is another available alternative that is superior to the first one under every criterion. ${ }^{250}$ Third, Arrow's theorem uses the "condition of nondictatorship." 251 In the context of the aggregation of individual preferences, this condition requires that social choices not always conform to any one individual's preferences. ${ }^{252}$ In this article, "nondictatorship" is imposed by axiom VI's requirement that the outcome under any single criterion not always determine the outcome of the choice process. 253

The remaining condition of Arrow's theorem is "independence of irrelevant alternatives." 254 This condition requires both that the choice among a fixed set of alternatives depend only on the ordinal rankings of those alternatives under the given criteria and that the addition of other alternatives in the comparison not change the rankings of the original choices. ${ }^{255}$ As an example, consider a choice among four candidates, $\mathrm{W}, \mathrm{X}, \mathrm{Y}$, and $Z$, under seven criteria. ${ }^{250}$ Suppose that the choice process operates first by assigning each candidate one point for the lowest ranking under a criterion, two points for the second ranking, and so on up to the highest ranking, and then by choosing the candidate with the highest total number of points over all the criteria. Consider the following set of rankings:

$\begin{array}{llllllll}\quad \text { Criterion } & \text { 1 } & \mathbf{2} & \mathbf{3} & \mathbf{4} & \mathbf{5} & \mathbf{6} & \mathbf{7} \\ \text { Ranking } & & & & & & & \\ \text { First } & \text { W } & \text { X } & \text { Y } & \text { W } & \text { X } & \text { Y } & \text { W } \\ \text { Second } & \text { X } & \text { Y } & \text { Z } & \text { X } & \text { Y } & \text { Z } & \text { X } \\ \text { Third } & \text { Y } & \text { Z } & \text { W } & \text { Y } & \text { Z } & \text { W } & \text { Y } \\ \text { Fourth } & \text { Z } & \text { W } & \text { X } & \text { Z } & \text { W } & \text { X } & \text { Z }\end{array}$

247. See A. SEN, supra note 3, at 37 .

248. See p. 721 supra.

249. See A. SEN, supra note 3, at 37.

250. See pp. 724-25 supra.

251. See A. SEN, supra note 3 , at 38 .

252. See id.

253. See p. 743 supra.

254. See A. SEN, supra note 3, at 37 .

255. See id. at 37-38.

256. This example is taken from Fishburn, Paradoxes of Voting, 68 AM. J. Political ScI. 511 (1976). 


\section{Multicriteria Choice Processes}

When all four candidates are considered, $\mathrm{Y}$ will be chosen, but if $\mathrm{Z}$ is not included in the pool of applicants under consideration, $W$ will be the winner and $\mathrm{Y}$ will fall back to third in total points. In fact, $\mathrm{W}, \mathrm{X}$, and $\mathrm{Y}$ will rank exactly opposite in total points:

$\begin{array}{lcc} & \text { Total Points } \\ \text { Z included } & \text { Z deleted } \\ \text { W } & 18 & 15 \\ \mathrm{X} & 19 & 14 \\ \mathrm{Y} & 20 & 13 \\ \mathrm{Z} & 13 & \end{array}$

The outcome of the choice process between $\mathrm{W}, \mathrm{X}$, and $\mathrm{Y}$ depends on whether $\mathrm{Z}$ is also considered. The process therefore violates the condition of independence of irrelevant alternatives.

Unfortunately, difficulties with the independence-of-irrelevant-alternatives axiom preclude the clirect application of Arrow's theorem to judicial and administrative decisionmaking processes. First, it is difficult to determine whether MCCPs violate the condition. In order to make such a determination, one would either have to be considering a precisely specified choice process, such as in the example presented above, or one would need to have empirical or descriptive information about the effect of excluding certain alternatives from consideration. Many interesting MCCPs are not precisely defined, ${ }^{25 i}$ and most attempts to determine the effect of excluding certain alternatives from consideration would involve hypothetical speculation. Finally, even if violations of the condition of independence of irrelevant alternatives were easy to detect, the condition's legal and normative implications are not as meaningful or interesting as the implications of the axioms that replace it. 258

Arrow's general possibility theorem holds that not all of the conditions in his theorem can be satisfied by a choice process simultaneously. ${ }^{259}$ Appendices $B$ and $C$ link the nine textual axioms to the conditions of the theorem. Appendix B lists technical axioms that follow directly from the textual axioms. ${ }^{200}$ Appendix $C$ consists of two parts. First, the condition of independence of irrelevant alternatives is derived from some of the technical axioms. ${ }^{201}$ The technical axioms provide all of the additional conditions necessary for Arrow's theorem.262 The second half of Appendix

257. See, e.g., p. 727 supra (Harvard program does not specify explicitly how considerations under various criteria are combined to make choices between applicants); p. 736 supra (FCC does not give clear indication about how rankings under criteria are combined to choose single candidate from among many applicants for broadcast license).

258. For example, axiom IX can be related to the requirement that a court or agency adliere to precedent. See p. 744 supra.

259. See A. SEN, supra note 3 , at 37-38.

260. See pp. 768-72 infra.

261. This derivation is accomplished by proving Lemmas 1-3. Lemma 3 is the condition of independence of irrelevant altcrnatives. See pp. 772-76 infra; A. SEN, supra note 3, at $4 I$ (stating condition of independence of irrelevant alternatives in form similar to Lemma 3).

262. See pp. $765-66$ supra. 
C proves Arrow's theorem. ${ }^{263}$ Because the theorem holds that not all of the conditions can be satisfied simultaneously, and because the nine textual axioms imply all of Arrow's conditions, every MCCP must violate at least one of the nine textual axioms.

Appendix B. Translation of Roman Numeral Axioms into Arabic Number Axioms Used in Proofs in Appendix C.

In this appendix, the roman numeral axioms are transformed into an equivalent set of arabic number axioms, that are then employed in Appendix $\mathrm{C}$ to prove that the nine axioms presented in text cannot be simultaneously satisfied by an MCCP. All of the arabic number axioms are either direct "translations" of a roman numeral axiom into more formal terminology or axioms that are implied by a roman numeral axiom. This appendix presents each arabic numbered axiom and then explains the link between that axiom and the corresponding roman numeral axiom.

Before proceeding with the arabic numbered axioms a few definitions need to be provided: ${ }^{264}$

$\mathrm{E}=$ the set of all potential alternatives 265

$\mathrm{v}=$ a subset of $\mathrm{E}$

$N=$ a set of $n$ criteria, $c_{i}, i=1,2, \ldots, n$

$\mathrm{U}=$ the set of all real-valued functions on $\mathrm{EX} \mathrm{N}$

Given $a, b \varepsilon v ; u \varepsilon U, u\left(a, c_{i}\right) \geq u\left(b, c_{i}\right)$ means $a$ is at least as good as $b$ under criterion $i$.

1. Axiom 1: $\exists \mathrm{C}(\mathrm{v}, \mathfrak{u})$, a single-valued choice function, which depends on $v$, the set of alternatives under consideration, and on the numbers assigned to each alternative under each criterion by the function $u$.

263. See pp. $776-78$ infra.

264. It is assumed in this appendix and in Appendix $\mathbf{C}$ that the reader is familiar with elementary logical and mathematical symbols. For readers who do not have such familiarity, the commonly used symbols and their meanings are as follows:

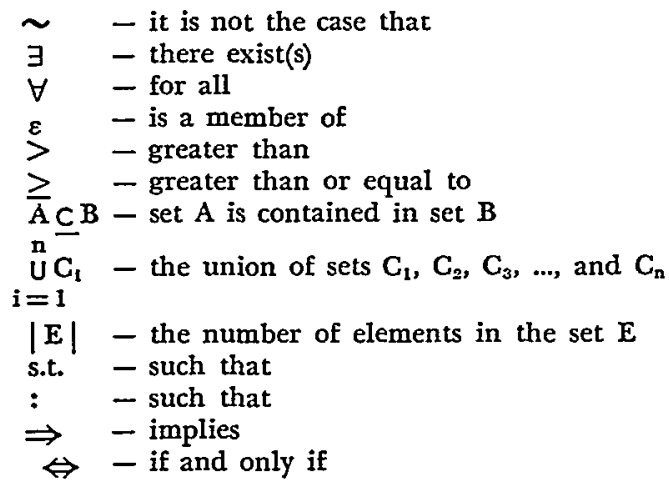

265. "Potential alternatives" here is meant in the sense of axiom 2 in this appendix, see p. 769 infra. A "potential alternative" is one that will be chosen if no other alternative is available. 
This axiom is equivalent to axiom $I$ in the text. ${ }^{266}$ Both axioms specify that the MCCP chooses a single alternative from the set of alternatives under consideration.

2. Axiom 2: $|\mathrm{E}| \geq 3$. In addition, $\forall \mathrm{u}^{\mathrm{i}} \varepsilon \mathrm{U}, \mathrm{C}\left(\mathrm{a}, \mathrm{u}^{\mathrm{i}}\right)=\mathrm{a} \forall \mathrm{a} \varepsilon \mathrm{E}$.

The first part of this axiom states that $E$, the set of potential alternatives, contains at least three members. This part of axiom 2 is simply a technical statement of axiom II in text. ${ }^{267}$

The second part of axiom 2 follows from the definition of potential alternatives as those that will be selected if there are no other alternatives under consideration.

3. Axiom 3: $\mathrm{C}\left(\mathrm{v}, \mathrm{u}^{\mathrm{i}}\right)$ is defined $\forall \mathrm{v}, \forall \mathbf{u}^{\mathrm{i}} \varepsilon \mathrm{U}$.

Axiom 3 states that regardless of the set of numbers assigned to the alternatives by the function $\mathbf{u}^{\mathbf{i}}$, which establishes rankings under various criteria, the choice function will generate an "answer" when possible choices are limited to any subset, v, of the set of all potential alternatives. The axiom does not specify the form of the "answer." It may be that no choice or more than one alternative is the "answer." Other axioms such as axioms 1 and 2 put restrictions on what the answer can be. ${ }^{268}$

Axiom 3 follows directly from axiom III in text. ${ }^{269}$ Axiom III states that the choice process can consider any potential alternative regardless of the particular characteristics it possesses. ${ }^{2}{ }^{i 0} \mathrm{But}$ axiom 3 states only that the choice function is defined for any subset, $\mathrm{v}$, of the set $\mathrm{E}$ of all potential alternatives.

4. Axiom 4: For every $\mathrm{u}^{1}, \mathrm{u}^{2} \varepsilon \mathrm{U}, \forall \mathrm{v} \subseteq \mathrm{E}$, if $\exists \mathrm{n}+1$ numbers $\alpha, \beta_{1}>0$, $\beta_{2}>0, \ldots, \beta_{\mathrm{n}}>0$ such that $\forall \mathrm{c}_{\mathrm{i}} \varepsilon \mathrm{N}$, and $\forall \mathrm{a} \varepsilon \mathrm{E}, \mathrm{u}^{1}\left(\mathrm{a}, \mathrm{c}_{\mathrm{i}}\right)=\alpha+\beta_{\mathrm{i}} \mathrm{u}^{2}\left(\mathrm{a}, \mathrm{c}_{\mathrm{i}}\right)$ then $\mathrm{C}\left(\mathrm{v}, \mathrm{u}^{1}\right)=\mathrm{C}\left(\mathrm{v}, \mathrm{u}^{2}\right)$.

This axiom states that if the numbers used to represent a ranking within any one criterion are rescaled by a "positive linear transformation" consisting of multiplying the original numbers by some positive number or of adding the same number to each of the numbers or both, there will be no change in the outcome of the choice function over any set of potential alternatives, v. For example, suppose that a composite MCAT score is one of the criteria for making decisions between candidates for admission to medical school. If axiom 4 applies, the choice will be unaffected if the MCAT scores are rescaled by a positive linear transformation. In other words, the choice will not depend on whether the original MCAT score is used or each MCAT score is multiplied by the same positive number, $\beta$, and then increased by the same number, $\alpha$.

This arabic numbered axiom follows from axiom IV in text. ${ }^{271}$ Axiom IV allows "quarternary comparisons" between the degree of preference

266. See pp. 720-21 supra.

267. See p. 721 supra.

268. See pp. 768-69 supra.

269. See p. 721 supra.

270. See id.

271. See pp. 721-22 supra. 
under any single criterion. Thus one can make a comparison like "alternative $a$ is preferred to alternative $b$ under criterion two by five times as much as alternative $c$ is preferred to alternative $d$ under the same criterion." What axiom IV does not permit is a process that combines such comparisons into a choice by using a set of absolute weights, 272 by translating each comparison onto a single absolute scale, ${ }^{273}$ or by assigning importance to a criterion not on the sole basis of the relative size of preferences under the criterion but by reference to the score on an absolute scale. ${ }^{274}$ If axiom IV holds, then the choice will be unaffected if the numbers representing the ranking under any criterion are rescaled by a positive linear transformation since the size of preferences under one criterion will not be linked to the size of preferences under any other criterion by absolute weights or by a common scale. Only the relative size of preferences under any criterion, as opposed to some absolute score for the criterion, will affect the choice.

5. Axiom 5: $\exists$ a complete binary relation, $\mathrm{R}$, that rationalizes $\mathrm{C}$. (A relation, $\mathrm{R}$, rationalizes a choice function if $\forall \mathrm{v} \varepsilon \mathrm{E}, \mathrm{C}(\mathrm{v})=(\mathrm{x} \varepsilon \mathrm{v}: \forall \mathrm{y} \varepsilon \mathrm{v}$, $\mathrm{xRy}$ ); $\mathrm{R}$ can be thought of as "is at least as desirable an alternative as.")

The first part of axiom 5, stating that there exists a complete binary relation, is merely a technical statement of the first half of axiom $V$ in text. ${ }^{275}$ The existence of a complete binary relation means that between

272. Suppose that a medical school admits students on the basis of two criteria: a 0 to 100 score on an aptitude test and a 0 to 4 college grade point average. Assume the school uses absolute weights to combine the two criteria by adding 25 times grade point average to the aptitude scores and choosing the candidate with the highest aggregate score. If the school were to scale down the aptitude test scores by dividing them by 100 , greater prominence would be placed on grade point average so that some choices between possible candidates would be changed. Specifically, after the "scaling down," a 0.04 difference in grade point average would compensate for a 100-point difference in test score while previously a 0.04 difference in grade point average would only have compensated for a one-point change in test score.

273. Translating each comparison onto a single absolute scale is equivalent to using absolute weights. By using absolute weights, differences in scores under different criteria become directly comparable. The weights translate the point differences under one criterion into equivalent point differences under others. One could choose the scale of quarternary comparison units under any one criterion and use the weights to translate differences under any other criterion into units of that scale. The net result would be a common absolute scale.

274. Suppose that academic potential is one of the criteria for admission to medical school and that aptitude test scores are used to rank applicants under that criterion. If the absolute difference between candidates' scores has significance for the importance of the criterion, then rescaling the aptitude test scores might affect whether or not a particular applicant is chosen. On the other hand, if only relative differences between candidates matter, then rescaling should have no effect on any outcome. Consider the case in which $A$ has a score of $800, B$ a score of 750, and $C$ a score of 725 . If an admissions committee weights the criterion against others by reference to absolute differences, then a rescaling in which the scores become 800,790 , and 785 respectively would dilute the impact of the criterion. Yet if only relative differences were considered, then the gap between $A$ and $B$ would still be twice as much as the gap between $B$ and $C$ after the rescaling, and the choice process would be unaffected.

275. See pp. 722-23 supra. 


\section{Multicriteria Choice Processes}

any two alternatives the relation indicates that one is more desirable than the other or that the two are equally desirable. ${ }^{270}$

The second part of axiom 5 states that $R$ "rationalizes" the choice function, $C$. This means that for any set of alternatives, $v$, if $x$ is an alternative that is in the subset chosen under the choice function, then the relation xRy will hold for all alternatives $y$ in the set v. "xRy" can be reacl as "alternative $\mathrm{x}$ is at least as good as alternative $\mathrm{y} . "$

The second part of axiom 5 follows from the second part of axiom V in text and from axioms 1 and 7.277 The second part of axiom $V$ states that from any two alternatives, the most desirable alternative must be chosen if one is more desirable than the other. Axiom 5 goes beyond the case of two alternatives to state that the choice function will select an alternative that is at least as desirable as all the other possible alernatives. To see how that axiom follows from axiom 1 , axiom 7 , and the second half of axiom $\mathrm{V}$, consider a series of pairwise comparisons of alternatives using the choice function: the first and second alternative are compared and the winner is compared to the third alternative, the winner of that comparison is compared to the fourth alternative, and so on until a final choice emerges from a comparison involving the last alternative. Axiom 1 guarantees that each pairwise comparison will have a single winner, and axiom 7 implies that the order in which the elements are set up for pairwise comparison will not affect the outcome. Suppose alternative $F$ is the outcome. $F$ could then be designated as the first element in the sequence for pairwise comparison. $F$ would then be compared sequentially to each other available alternative. But by the second half of axiom $V, F$ would have to be at least as desirable as any other available alternative in order to survive as the winner of such a sequential pairwise comparison with all the other alternatives.

6. Axiom 6: $\exists$ no $\mathrm{i}$ such that $\forall \mathrm{a}, \mathrm{b} \varepsilon \mathrm{E}, \mathrm{u}\left(\mathrm{a}, \mathrm{c}_{\mathrm{i}}\right)>\mathrm{u}\left(\mathrm{b}, \mathrm{c}_{\mathrm{i}}\right)$ implies that $\mathrm{C}((\mathrm{a}, \mathrm{b}), \mathrm{u})=\mathrm{a}$ where $\mathrm{u}$ is the function chosen to scale rankings under each criterion.

This axiom states that there is no one criterion such that the outcomes on that criterion determine the choice between any two potential alternatives. The axiom is a technical restatement of axiom VI in text. 278

7. Axiom 7: $\forall \mathrm{v} \subseteq \mathrm{E}$, given $\mathrm{n}$ subsets, $\mathrm{v}_{\mathrm{i}}$, of $\mathrm{v}$ such that $\bigcup_{\mathrm{i}=\mathrm{I}}^{\mathrm{n}} \mathrm{v}_{\mathrm{i}}=\mathrm{v}$, then $C(v, u)=C\left(\bigcup_{i=1}^{n} C\left(v_{i}, u\right)\right)$.

This axiom states that the outcome of a choice process will not depend on whether a choice is made from the entire set of alternatives or is made from a subset of "winners" chosen by applying the choice function to subsets the union of which is the entire set. The axiom is equivalent to axiom VII in text. ${ }^{270}$

276. See p. 722 supra (explaining "complete binary relation").

277. See pp. 722-23 supra.

278. See p. 723 supra.

279. See pp. 723-24 supra. 
8. Axiom 8 : $\forall \mathrm{v} \subseteq \underline{\mathrm{C}} \mathrm{E}$, if $\mathrm{a}, \mathrm{b} \varepsilon \mathrm{v}$ and if $\mathrm{u}\left(\mathrm{a}, \mathrm{c}_{\mathrm{i}}\right)>\mathrm{u}\left(\mathrm{b}, \mathrm{c}_{\mathrm{i}}\right) \forall \mathrm{i}$ then $\mathrm{b} \notin \mathrm{C}(\mathrm{v}, \mathrm{u})$. This axiom states that if $a$ is superior to $b$ under every criterion then $\mathrm{b}$ cannot be chosen when $\mathrm{a}$ and $\mathrm{b}$ are both alternatives. The axiom is a technical restatement of axiom VIII in text. ${ }^{280}$

9. Axiom 9: $\forall \mathrm{a}, \mathrm{b} \varepsilon \mathrm{E}, \forall \mathrm{u}^{1} \varepsilon \mathrm{U}$, if $w, z \varepsilon \mathrm{E}$ and $\mathrm{u}^{0} \varepsilon \mathrm{U}$ such that $\forall c_{\mathrm{l}} \varepsilon \mathrm{N}$, $u^{1}\left(a, c_{i}\right)=u^{0}\left(w, c_{i}\right)$, and $u^{1}\left(b, c_{i}\right)=u^{0}\left(z, c_{i}\right)$

then if $z \notin C\left((w, z), u^{0}\right)$ then $b \& C\left((a, b), u^{1}\right)$.

This axiom states that if a has the same categorical rankings as $w$, and $\mathrm{b}$ has the same categorical rankings as $z$, then if $\mathrm{b}$ is not chosen over $\mathrm{a}$, $z$ will not be chosen over $w$. The axiom is equivalent to axiom IX in text.281

\section{Appendix C: Proof of the Inconsistency of the Nine Axioms}

Two tasks are performed in this appendix. First, the nine axioms in Appendix A are used to derive the single condition of Arrow's general possibility theorem, independence of irrelevant alternatives, that is not already incorporated in one of the axioms. ${ }^{282}$ Lemmas 1 and 2 provide groundwork for the derivation of independence of irrelevant alternatives as Lemma 3. The second part of the appendix, Lemmas 4 and 5 and a final theorem, provides a proof of Arrow's general possibility theorem.

\section{A. Deriving the Independence of Irrelevant Alternatives}

1. Lemma $1: \mathrm{R}$, the binary relation that rationalizes the choice function, ${ }^{283}$ is

(i) unique

(ii) total $(\forall x, y \in E, x R y \text { or } y R x)^{28 \pm}$

(iii) reflexive $(\forall x \in E, x R x)$

(iv) transitive $(\forall x, y, z \in E, x R y$ and $y R z \Rightarrow x R z)$.

Proof:285

(i) Uniqueness: Uniqueness follows directly from the single-valuedness of the choice function postulated in axiom 1.286 For any two potential

280. See pp. 724-25 supra.

281. See p. 725 supra.

282. See pp. 765-68 supra (explaining both independence of irrelevant alternatives and use of Arrow's general possibility theorem in Appendix C proof that nine axioms used in text cannot all apply simultaneously to MCCP).

283. See pp. 770-71 supra (axiom 5).

284. R signifies the relation between alternatives. $x R y$ can be thought of as " $x$ is at least as good as y."

285. The bulk of this proof is taken from Plott, Path Independence, Rationality and Social Choice, 41 ECONOMETRICA 1075, 1086 (1973).

286. See pp. 768-69 supra (axiom 1). Henceforth in this appendix, no cross-references will be made to arabic-numbered axioms when the axiom number is stated in the text of the appendix. All of these axioms are set out in Appendix B, pp. 768.72 supra. 
alternatives, $\mathrm{x}$ and $\mathrm{y}$, the choice function must choose one of them if they are the only two potential alternatives considered. Suppose that $\mathbf{x}$ is chosen, i.e., $\mathrm{C}(\mathrm{x}, \mathrm{y})=\mathrm{x}$. Then it must be true that $\mathrm{xRy}$ and $\sim \mathrm{yRx}$ since otherwise the choice function would not be single-valued.287 Examining the outcome of the choice function for each pair of potential alternatives will define the unique relation, $R$, between each pair of potential alternatives that rationalizes the choice function.

(ii) Totality: Axiom 3 postulates that the choice function is defined for all sets of potential alternatives. Axiom 5 requires that the relation $\mathrm{R}$ rationalize the choice function. As a result, it must be that $x R y$ or $y R x$ for all potential alternatives $\mathrm{x}$ and $\mathrm{y}$.

(iii) Reflexivity: Under a relation $\mathrm{R}$ of the type "is at least as good as," an element is at least as good as itself so that for any potential alternative $\mathrm{x}$ it must be the case that $\mathrm{xRx}$. More formally, axiom 2 requires that a potential alternative must be chosen if it is the only alternative available. Thus for any potential alternative $\mathrm{x}, \mathrm{C}(\mathrm{x})=\mathrm{x}$ so that it must be the case that $\mathrm{xRx}$.

(iv) Transitivity: Consider a set of three potential alternatives $\{x, y, z\}=$ v. Suppose $x=C\{x, y\}, y=C\{y, z\}$. Axiom $7 \Rightarrow x=C\{x, y\}=C\{C\{x\}$, $\mathrm{C}\{\mathrm{y}, \mathrm{z}\}\}=\mathrm{C}\{\mathrm{C}\{\mathrm{x}, \mathrm{y}\}, \mathrm{C}\{\mathrm{z}\}\}=\mathrm{C}\{\mathrm{x}, \mathrm{z}\}$. Axiom $5 \Rightarrow \mathrm{R}$ rationalizes $\mathrm{C}$. Therefore, we have

(1) $\quad \mathrm{xRy}, \sim \mathrm{yRx}, \mathrm{yRz}, \sim \mathrm{zRy} \Rightarrow \mathrm{xRz}, \sim \mathrm{zRx}$.

But single-valuedness under axiom $1 \Rightarrow[\forall a, b \varepsilon E, a R b \Rightarrow \sim b R a]$. Therefore ( $\mathrm{I}$ ) reduces to

(2) $\quad x R y, y R z \Rightarrow x R z$,

and transitivity is proved.

2. Lemma 2: For every $\mathrm{u}^{1}, \mathrm{u}^{2} \varepsilon \mathrm{U}, \forall \mathrm{v} \subseteq \mathrm{E}$, if $\exists 2 \mathrm{n}$ numbers $\alpha_{1}, \ldots, \alpha_{\mathrm{n}}$, $\beta_{1}>0, \ldots, \beta_{\mathrm{n}}>0$ s.t. $\forall c_{1} \varepsilon N$ and $\forall a \varepsilon E$ $\mathrm{u}^{1}\left(\mathrm{a}, \mathrm{c}_{\mathrm{i}}\right)=\alpha_{\mathrm{i}}+\beta_{\mathrm{i}} \mathrm{u}^{2}\left(\mathrm{a}, \mathrm{c}_{\mathrm{i}}\right)$ then $\mathrm{C}\left(\mathrm{v}, \mathrm{u}^{1}\right)=\mathrm{C}\left(\mathrm{v}, \mathrm{u}^{2}\right)$.

Proof:288 Choose arbitrary $\mathrm{u}^{1} \varepsilon \mathrm{U} ; \alpha_{1}, \ldots, \alpha_{\mathrm{n}} ; \beta_{1}>0, \ldots, \beta_{\mathrm{n}}>0$ and construct $u^{0} \varepsilon U$ s.t. $\forall z \in E, \forall c_{1} \varepsilon N, u^{0}\left(z, c_{1}\right)=\alpha_{1}+\beta_{i} u^{1}\left(z, c_{i}\right)$. We must show $\mathrm{C}\left(\mathrm{v}, \mathrm{u}^{1}\right)=\mathrm{C}\left(\mathrm{v}, \mathrm{u}^{0}\right), \forall \mathrm{v} \subseteq \underline{\mathrm{C}}$. Construct $\mathrm{u}^{2} \varepsilon \mathrm{U}$ s.t. $\forall \mathrm{z} \varepsilon \mathrm{E}$ and $\forall \mathrm{c}_{\mathrm{i}} \varepsilon \mathrm{N}$, $\mathrm{u}^{2}\left(\mathrm{z}, \mathrm{c}_{\mathrm{i}}\right)=1+\beta_{1}^{\prime} \mathrm{u}^{1}\left(\mathrm{z}, \mathrm{c}_{\mathrm{i}}\right)$ where $\beta_{1}^{\prime}$ is defined by:

(i) pick arbitrary $\theta<\min _{\mathrm{j}} \epsilon_{\mathrm{x}}\left\{\alpha_{\mathrm{j}}\right\}^{289}$

(ii) $\beta_{1}^{\prime} \equiv \frac{\beta_{1}}{\alpha_{1}-\theta}$.

287. See pp. 768-69 supra (choice function must be single-valued); pp. 770-71 supra (definition of "rationalizes" and requirement that $R$ rationalizes choice function).

288. This proof is taken from D'Aspremont \& Gevers, Equity and the Informational Basis of Collective Choice, 44 Rev. Econ. Stud. 199, 205 (1977).

289. The expression $\min _{1} \in \mathbb{N}\left\{\alpha_{1}\right\}$ means the smallest value from the set of all the numbers $a_{j}$. 
Now, by axiom 4

$$
\mathrm{C}\left(\mathrm{v}, \mathrm{u}^{2}\right)=\mathrm{C}\left(\mathrm{v}, \mathrm{u}^{1}\right), \forall \mathrm{v} \underline{\mathrm{C}} \mathrm{E}
$$

Now write

So

$$
\begin{aligned}
u^{1}\left(z, c_{i}\right) & =\left[u^{2}\left(z, c_{i}\right)-1\right]\left[\frac{\alpha_{i}-\theta}{\beta_{i}}\right] \\
u^{0}\left(z, c_{i}\right) & =\alpha_{i}+\beta_{i} u^{1}\left(z, c_{i}\right) \\
& =\alpha_{i}+\beta_{i}\left[\frac{\alpha_{i}-\theta}{\beta_{i}}\right]\left[u^{2}\left(z, c_{i}\right)-1\right] \\
& =\alpha_{i}+\left(\alpha_{i}-\theta\right)\left[u^{2}\left(z, c_{i}\right)\right]+\theta-\alpha_{i} \\
& =\theta+\left(\alpha_{i}-\theta\right)\left[u^{2}\left(z, c_{i}\right)\right] .
\end{aligned}
$$

Now, by axiom 4

$$
\mathrm{C}\left(\mathrm{v}, \mathrm{u}^{0}\right)=\mathrm{C}\left(\mathrm{v}, \mathrm{u}^{2}\right) \forall \mathrm{v} \subseteq \mathrm{E} .
$$

Now, putting (A) and (B) together we get $C\left(v, u^{0}\right)=C\left(v, u^{1}\right) \forall v \subseteq E$.

Q.E.D.

\section{Definitions:}

Definition: for each $c_{i}, \forall u^{k} \varepsilon U, \forall a, b \varepsilon E$,

$$
\mathrm{aR}_{\mathrm{i}} \mathrm{b} \Leftrightarrow \mathrm{u}^{\mathrm{k}}\left(\mathrm{a}, \mathrm{c}_{\mathrm{i}}\right) \geq \mathrm{u}^{\mathrm{k}}\left(\mathrm{b}, \mathrm{c}_{\mathrm{i}}\right) \text {. }
$$

Definition: $\mathrm{aP}_{\mathrm{i}} \mathrm{b} \Leftrightarrow \mathrm{aR} \mathrm{k}_{\mathrm{i}} \mathrm{b}$ and $\sim \mathrm{bR}_{\mathrm{i}} \mathrm{a}$.

4. Lemma 3: Given $\mathrm{u}^{\mathrm{j}}, \mathrm{u}^{\mathrm{k}} \varepsilon \mathrm{U}, \forall \mathrm{v} \varepsilon \mathrm{E}$ s.t. $\mathrm{v}$ has at least two elements, if $\forall \mathrm{a}, \mathrm{b} \varepsilon v$ and $\forall c_{i} \varepsilon N$ it is true that $a R_{i} b \Leftrightarrow a \mathrm{R}_{\mathrm{i}} \mathrm{b}$ then $\mathrm{G}\left(\mathrm{v}, \mathrm{u}^{\mathrm{k}}\right)=$ $\mathrm{G}\left(\mathrm{v}, \mathrm{u}^{\mathrm{j}}\right)$.

Proof: Pick arbitrary $a, b \varepsilon v, a \neq b$. Assume we have any $\vee \varepsilon E$ and any $\mathrm{u}^{1}, \mathrm{u}^{2} \varepsilon U$ with $\forall \mathrm{x}, \mathrm{y} \varepsilon \mathrm{E}, \mathrm{xR}^{1}{ }_{\mathrm{i}} \mathrm{y} \Leftrightarrow \mathrm{xR}^{2}{ }_{\mathrm{i}} \mathrm{y}, \forall \mathrm{c}_{\mathrm{i}} \varepsilon \mathrm{N}$. We must show $\mathrm{C}\left(\mathrm{v}, \mathrm{u}^{1}\right)=\mathrm{C}\left(\mathrm{v}, \mathrm{u}^{2}\right)$.

We will first show $\mathrm{C}\left(\{\mathrm{a}, \mathrm{b}\}, \mathrm{u}^{1}\right)=\mathrm{C}\left(\{\mathrm{a}, \mathrm{b}\}, \mathrm{u}^{2}\right)$. Assume, without loss of generality, that $\mathrm{aR}^{1} \mathrm{~b}$ (which $\left.\Rightarrow \mathrm{C}\left(\{\mathrm{a}, \mathrm{b}\}, \mathrm{u}^{1}\right)=\mathrm{a}\right)$. Now we know from the definition of $R^{k_{1}}$ that $u^{1}\left(a, c_{i}\right) \geq u^{1}\left(b, c_{i}\right) \Leftrightarrow u^{2}\left(a, c_{i}\right) \geq u^{2}\left(b, c_{i}\right)$ since $\mathrm{aR}^{1}{ }_{\mathrm{j}} \mathrm{b} \Leftrightarrow \mathrm{aR}^{2} \mathrm{~b}$.

Say

$$
\begin{aligned}
& u^{1}\left(a, c_{i}\right)=m_{1}^{i_{1}} \\
& u^{1}\left(b, c_{i}\right)=m^{i}{ }_{2} \\
& u^{2}\left(a, c_{i}\right)=n_{1}^{i} \\
& u^{2}\left(b, c_{i}\right)=n_{2}^{i}
\end{aligned}
$$


Construct $\mathbf{u}^{3}$ by setting ${ }^{200}$

$$
\begin{aligned}
& \alpha_{1}= \begin{cases}m_{1}^{1}-n_{1}^{1} & \text { if } n_{1}^{i}=n_{2}^{i} \\
m_{1}^{i}-\frac{m_{1}^{i}-m_{2}^{i}}{n_{1}^{i}-n_{2}^{i}} n_{1}^{i} & \text { if } n_{1}^{i} \neq n_{2}^{i}\end{cases} \\
& \beta_{1}= \begin{cases}1 & \text { if } n_{1}^{i_{1}}=n^{i_{2}} \\
\frac{m_{1}^{i_{1}}-m_{1}^{1}}{n^{i_{1}}-n^{i}} & \text { if } n^{i} \neq n_{2}^{i} .\end{cases}
\end{aligned}
$$

Now define $u^{3}\left(x, c_{i}\right)=\alpha_{1}+\beta_{i} u^{2}\left(x, c_{i}\right)$. By Lemma 2, $C\left(v, u^{3}\right)=C\left(v, u^{2}\right)$, $\forall v$. Specifically, for $v=\{a, b\}, C\left(\{a, b\}, u^{3}\right)=C\left(\{a, b\}, u^{2}\right)$. Note, however, that we can show $u^{3}\left(a, c_{i}\right)=m^{i}{ }_{1}$ and $u^{3}\left(b, c_{i}\right)=m_{2}{ }_{2}$ :

$$
\begin{aligned}
& u^{3}\left(a, c_{l}\right)= \\
& \text { case 1: } n^{i}{ }_{1}=n^{i} \text { then } u^{3}\left(a, c_{i}\right)=\alpha_{i}+\beta_{i} u^{2}\left(a, c_{i}\right)= \\
& \mathrm{m}^{\mathrm{i}}{ }_{1}-\mathrm{n}^{\mathbf{i}}{ }_{1}+\mathrm{n}^{\mathrm{i}}{ }_{\mathbf{1}}=\mathrm{m}^{\mathrm{i}}{ }_{\mathbf{1}} \text {. } \\
& \text { case 2: } \mathrm{n}^{\mathrm{i}}{ }_{1} \neq \mathrm{n}^{\mathrm{i}}{ }_{2} \text { then } \mathrm{u}^{3}\left(\mathrm{a}, \mathrm{c}_{\mathrm{i}}\right)=\alpha_{\mathrm{i}}+\beta_{1} \mathrm{u}^{2}\left(\mathrm{a}, \mathrm{c}_{\mathrm{i}}\right)=
\end{aligned}
$$

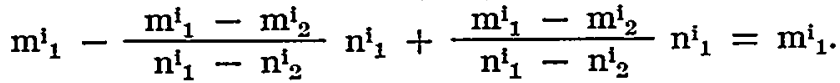

$$
\begin{aligned}
& u^{3}\left(b, c_{i}\right)= \\
& \text { case 1: } n^{i}{ }_{1}=n^{i}{ }_{2} \text { then } u^{3}\left(b, c_{i}\right)=\alpha_{i}+\beta_{i} u^{2}\left(b, c_{i}\right)=
\end{aligned}
$$

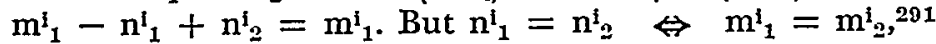

$$
\begin{aligned}
& \text { so } \mathrm{u}^{3}\left(\mathrm{~b}, \mathrm{c}_{\mathrm{i}}\right)=\mathrm{m}_{1}^{{ }_{1}}=\mathrm{m}_{2}^{\mathrm{i}} \text {. } \\
& \text { case 2: } n^{i} \neq n_{2}{ }_{2} \text { then } u^{3}\left(b, c_{i}\right)=\alpha_{i}+\beta_{i} u^{2}\left(b, c_{i}\right)=
\end{aligned}
$$

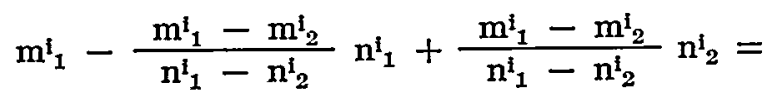

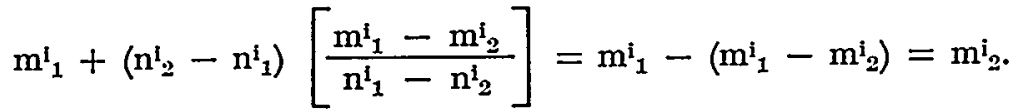

Now by axiom 9 and the single-valuedness of the choice function postulated under axiom $1, C\left(\{a, b\}, u^{3}\right)=C\left(\{a, b\}, u^{1}\right)$ since the values of $u^{j}$ for each of the choice functions are the same for all alternatives and for all criteria. But we constructed $\mathrm{u}^{3}$ so that by Lemma $2, \mathrm{C}\left(\{\mathrm{a}, \mathrm{b}\}, \mathrm{u}^{3}\right)=$ $\mathrm{C}\left(\{\mathrm{a}, \mathrm{b}\}, \mathrm{u}^{2}\right)$. As a result, it must be that $\mathrm{C}\left(\{\mathrm{a}, \mathrm{b}\}, \mathrm{u}^{1}\right)=\mathrm{C}\left(\{\mathrm{a}, \mathrm{b}\}, \mathrm{u}^{2}\right)$.

290. Note that $\left[m_{1}^{1}>m_{2}^{1} \Leftrightarrow n_{1}^{1}>n_{2}^{1}\right] \Rightarrow \frac{m_{1}^{1}-m_{1}^{1}}{n_{1}^{1}-n_{1}^{1}}>0$ if $n_{1}^{1} \neq n_{12}^{1}$.

291. By definition, $a R^{x_{1}} b \Leftrightarrow u^{k}\left(a, c_{1}\right) \geq u^{k}\left(b, c_{1}\right)$. See p. 774 supra. So if $\mathrm{n}_{1}=$ $\mathrm{n}^{\prime}$ then it must be the case that $\mathrm{aR}^{2}{ }_{1} \mathrm{~b}$ and $\mathrm{bR}^{2}{ }_{1} \mathrm{a}$. But, by the assumptions of Lemma 3 , $\mathrm{xR}_{1}^{1} \mathrm{y} \Leftrightarrow \mathrm{xR}_{1}^{2} \mathrm{y}$ for all elements $\mathrm{x}, \mathrm{y}$ in $\mathrm{E}$. Now $\left[\mathrm{aR}^{2} \mathrm{~b}_{1}\right.$ and $\left.\mathrm{bR}^{2}{ }_{1} \mathrm{a}\right] \Leftrightarrow\left[\mathrm{aR}_{1}^{1} \mathrm{~b}\right.$ and $\left.b R^{1} a\right]$. By the definition at the beginning of this note, $\left[a R^{1}{ }_{1} b\right.$ and $\left.b_{R^{1}} a\right]$ implies that $\mathrm{m}_{1}^{1}=\mathrm{m}_{2}^{1}$ since $\mathrm{m}_{1}^{1}=\mathrm{u}^{2}\left(\mathrm{a}, \mathrm{c}_{1}\right)$ and $\mathrm{m}_{2}^{1}=\mathfrak{u}^{1}\left(\mathrm{~b}, \mathrm{c}_{1}\right)$. So we have shown in this note that $n_{1}^{1}=n_{2}^{1} \Leftrightarrow m_{1}^{1}=m_{2}^{1}$. 
By axiom 7 any choice over a set $\mathrm{V}$ can be decomposed into a series of choices between pairs of alternatives without affecting the overall choice. As a result, $C\left(\{a, b\}, \mathbf{u}^{1}\right)=C\left(\{a, b\}, u^{2}\right)$ for any two elements of any subset of $\mathrm{E}$ with more than two elements $\Rightarrow \mathrm{C}\left(\mathrm{v}, \mathrm{u}^{1}\right)=\mathrm{C}\left(\mathrm{v}, \mathrm{u}^{2}\right) \forall \mathrm{v} \varepsilon \mathrm{E}$ with more than two elements.

Q.E.D.

B. Proof and Application of Arrow's General Possibility Theorem ${ }^{202}$

\section{Definitions:}

Definition: A set of criteria, $\mathrm{C}$, is almost decisive for $\mathrm{x}$ against $\mathrm{y}$ if $\left[\mathrm{xP}_{\mathrm{i}} \mathrm{y} \forall \mathrm{c}_{\mathrm{i}} \varepsilon \mathcal{C}\right.$ and $\left.\mathrm{yP}_{\mathrm{i}} \mathrm{x} \forall \mathrm{c}_{\mathrm{i}} \notin \mathrm{C}\right] \Rightarrow \mathrm{xPy} .{ }^{203}$

Definition: A set of criteria, $\mathrm{C}$, is decisive for $\mathrm{x}$ against $\mathrm{y}$ if $\left[\mathrm{xP}_{\mathrm{i}} \mathrm{y} \forall \mathrm{c}_{\mathrm{i}} \varepsilon\right.$ C $] \Rightarrow \mathrm{xPy}$.

Definition: $D(x, y)$ means $c_{j}$ is almost decisive for $x$ against $y$.

Definition: $\bar{D}(x, y)$ means $c_{j}$ is decisive for $x$ against $y$.

Note that $\bar{D}(x, y) \Rightarrow D(x, y)$. Also, $C(v, u)$ can be written $C\left(v ; R_{1}, \ldots, R_{n}\right)$.

2. Lemma 4: If any criterion, $\mathrm{c}_{\mathrm{j}}$, is almost decisive for an arbitrary ordered pair, $x, y$, then the choice process violates axiom 6 .

Proof: Assume $\exists \mathrm{x}, \mathrm{y} \varepsilon \mathrm{E}$ s.t. $\mathrm{D}(\mathrm{x}, \mathrm{y})$. By axiom 3 we can pick $\mathrm{z} \varepsilon \mathrm{E}$, $\mathrm{z} \neq \mathrm{x}, \mathrm{z} \neq \mathrm{y}$, and let $\mathrm{i}$ index all criteria, $c_{\mathrm{i}}$, other than the criterion, $c_{j}$, that is almost decisive between $x$ and $y$.

(1) Assume $\mathrm{xP}_{\mathrm{j}} \mathrm{y} \& \mathrm{yP} \mathrm{P}_{\mathrm{j}} \mathrm{z}$ and

$\mathrm{yP}_{\mathrm{i}} \mathrm{x} \& \mathrm{yP}_{\mathrm{i}} \mathrm{z}$.

Note that $\left[\mathrm{D}(\mathrm{x}, \mathrm{y}) \& \mathrm{xP}_{\mathrm{j}} \mathrm{y} \& \mathrm{yP}_{\mathrm{i}} \mathrm{x}\right] \Rightarrow \mathrm{xPy}$. Also $\left[\mathrm{yP}_{\mathrm{j}} \mathrm{z} \& \mathrm{yP} \mathrm{P}_{\mathrm{i}} \mathrm{z}\right] \Rightarrow \mathrm{y}=$ $\mathrm{C}\left(\{y, z\} ; R_{1}, \ldots, R_{n}\right) \Rightarrow y P z$, by axiom 8 . Next $x P y$ and $y P z \Rightarrow x P z$, from Lemma 1. By Lemma 3, the independence of irrelevant alternatives, the choice between $x$ and $z, C\left(\{x, z\} ; R_{1}, R_{2}, \ldots R_{n}\right)$ must not be affected by changes in the rankings under criteria for other pairs of alternatives. Hence, the assumptions concerning the rankings between $\mathrm{x}$ and $\mathrm{y}$ and between $y$ and $z$ under various criteria can be changed without affecting the fact that $\mathrm{x}$ will be chosen over $\mathrm{z}$. The only assumption with respect to the pair $\mathrm{x}, \mathrm{z}$ was that $\mathrm{xP}_{\mathrm{j}} \mathrm{z}$. Thus $\mathrm{xP}_{\mathrm{j}} \mathrm{z} \Rightarrow \mathrm{xPz}$, i.e., $\mathrm{D}(\mathrm{x}, \mathrm{y}) \Rightarrow \overline{\mathrm{D}}(\mathrm{x}, \mathrm{z})$.

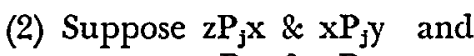
${ }_{2 P_{1}} \mathrm{x} \& \mathrm{yP}_{\mathrm{i}} \mathrm{x}$.

292. The proofs of Arrow's general possibility theorem are taken from A. SEN, supra note 3 , at $41-46$.

293. The relation $\mathbf{P}$ means "strictly preferred to." So $x P y$ is equivalent to [xRy and $\sim y R x$ ] where $R$ is the relation "is at least as good as." 
Now $\left[z P_{1} x \& z P_{j} x\right] \Rightarrow z P x$. Further $\left[D(x, y) \& x_{y} y \& y P_{i} x\right] \Rightarrow x P y$. Lemma $1 \Rightarrow{ }_{2 P y}$.

By similar reasoning to (1), $z \mathrm{P}_{\mathrm{j}} \mathrm{y} \Rightarrow \mathrm{zPy}$, so that $\mathrm{D}(\mathrm{x}, \mathrm{y}) \Rightarrow \overline{\mathrm{D}}(\mathrm{z}, \mathrm{y})$.

(3) By interchanging $y$ and $z$ in (2), we obtain: $D(x, z) \Rightarrow \bar{D}(y, z)$.

(4) In (1) replace $z$ with $x, y$ with $z$ and $x$ with $y$ to obtain: $D(y, z) \Rightarrow$ $\overline{\mathrm{D}}(\mathrm{y}, \mathrm{x})$.

(4') Using (1), (3), and (4), we get $D(x, y) \Rightarrow \bar{D}(x, z) \Rightarrow D(x, z) \Rightarrow$ $\bar{D}(y, z) \Rightarrow D(y, z) \Rightarrow \bar{D}(y, x)$.

So

(5) $\mathrm{D}(\mathrm{x}, \mathrm{y}) \Rightarrow \overline{\mathrm{D}}(\mathrm{y}, \mathrm{x})$.

Note that $D(x, y) \Rightarrow D(y, x)$ as an immediate result. Hence $D(y, x) \Rightarrow$ $[\bar{D}(y, z) \& \bar{D}(z, x) \& \bar{D}(x, y)]$ by interchanging $x$ and $y$ in (1), (2), and (5). By combining this with $\left(4^{\prime}\right)$ we get

$\mathrm{D}(\mathrm{y}, \mathrm{x}) \Rightarrow[\overline{\mathrm{D}}(\mathrm{y}, \mathrm{z}) \& \overline{\mathrm{D}}(\mathrm{z}, \mathrm{x}) \& \overline{\mathrm{D}}(\mathrm{x}, \mathrm{z}) \& \overline{\mathrm{D}}(\mathrm{z}, \mathrm{y}) \& \overline{\mathrm{D}}(\mathrm{x}, \mathrm{y}) \& \overline{\mathrm{D}}(\mathrm{y}, \mathrm{x})]$ which means $c_{j}$ is decisive for any ordered pair from the set $\{x, y, z\}$. This implies $c_{j}$ is decisive for any $a, b \varepsilon E$. To see this, note that, for any pair $a, b \in E$ there are three cases:

case $1: a$ and $b$ are the same as $x$ and $y$. Then, by the result above, $c_{j}$ is decisive for a against $b$.

case 2: if only one of $a$ and $b$ is the same as $x$ or $y$, (say $a=x$ without loss of generality) then take $y$ and form the three element set $\{a, b, y\}$. By the argument above, $\bar{D}(\mathrm{a}, \mathrm{b})$.

case 3: neither a nor $b$ is the same as $x$ or $y$. First, form $\{x, y, a\}$. We know $\mathrm{D}(\mathrm{x}, \mathrm{y}) \Rightarrow \overline{\mathrm{D}}(\mathrm{x}, \mathrm{a}) \Rightarrow \overline{\mathrm{D}}(\mathrm{x}, \mathrm{a})$. Now form $\{\mathrm{x}, \mathrm{a}, \mathrm{b}\}$. We know $D(x, a) \Rightarrow \bar{D}(a, b) \& \bar{D}(b, a)$. Hence, given $D(x, y)$ for some arbitrary $\mathrm{x}, \mathrm{y} \Rightarrow \forall \mathrm{a}, \mathrm{b} \varepsilon \mathrm{E}, \overline{\mathrm{D}}(\mathrm{a}, \mathrm{b})(\& \overline{\mathrm{D}}(\mathrm{b}, \mathrm{a}))$. But this means $\mathrm{aP} \mathrm{P}_{\mathrm{j}} \mathrm{b} \Rightarrow \mathrm{aPb}$ which $\Rightarrow a=C\left(\{a, b\} ; R_{1}, \ldots, R_{n}\right)$, which violates axiom 6 .

Q.E.D.

3. Lemma 5: It must be the case that some criterion, $c_{\mathrm{j}}$, is almost decisive for some pair, $x, y$.

Proof: Axiom 8 implies that for any pair of applicants, $\mathrm{x}$ and $\mathrm{y}$, the set of all criteria, $\left\{c_{i}\right\}$ for $i=1,2, \ldots, n$, is decisive because the axiom establishes that an alternative that is preferred over another one under every criterion will be chosen over that other one. From among the set of sets of criteria that are decisive between some pair (not necessarily the same pair) choose one of minimal size. Call this set $\hat{O}$ and let it be decisive, and therefore almost decisive, for $\mathrm{x}$ against $\mathrm{y}$. If we can show that there is only one criterion in 0 , then the Lemma is true.

Assume there are two or more categories in ô. Now divide ô into $\hat{O}_{1}$ (containing one criterion from $\hat{\mathrm{O}}$ ) and $\mathrm{O}_{2}$ (containing all the other criteria in $O_{\text {). }}$ Let $\mathrm{O}_{3}$ be the set of all criteria not in ô. 
By axiom 3, the choice process can operate on alternatives with any set of rankings under the criteria, i.e., we can choose any $\mathrm{u}^{\mathrm{i}} \varepsilon \mathrm{U}$. By axiom 2, there is at least one potential alternative other than $x$ and $y$. Call that alternative $z$ and consider the following set of rankings:

(1) $\forall c_{\mathrm{i}} \varepsilon \hat{\mathrm{O}}_{1}, \mathrm{xP}_{\mathrm{i}} \mathrm{y} \& \mathrm{yP} \mathrm{i} \mathrm{z}$

(2) $\forall c_{j} \varepsilon \hat{O}_{2}, z_{j} x \& \mathrm{xP}_{\mathrm{j}} \mathrm{y}$

(3) $\forall \mathrm{c}_{\mathrm{k}} \varepsilon \hat{O}_{3}, \mathrm{yP}_{\mathrm{k}} \mathrm{z} \& \mathrm{zP}_{\mathrm{k}} \mathrm{x}$.

Since $\hat{O}=\hat{O}_{1} \cup \hat{O}_{2}$ is almost decisive for $(\mathrm{x}, \mathrm{y}), \mathrm{xP}_{\mathrm{m}} \mathrm{y} \forall \mathrm{c}_{\mathrm{m}} \varepsilon$ Ô \& $\mathrm{yP}_{\mathrm{k}} \mathrm{x}^{294}$ $\forall c_{\mathrm{k}} \varepsilon \mathrm{O}_{3} \Rightarrow \mathrm{xPy}$.

Consider the pair of alternatives $(\mathrm{y}, \mathrm{z})$. Now $\mathrm{zP}_{\mathrm{j}} \mathrm{y} \forall \mathrm{c}_{\mathrm{j}} \varepsilon \hat{\mathrm{O}}_{2}$ and $\mathrm{yP}_{\mathrm{m}} \mathrm{z} \forall \mathrm{c}_{\mathrm{m}}$ $\varepsilon \mathrm{O}_{1} \cup \mathrm{O}_{3}$. If $z \mathrm{Py}$, then $\hat{O}_{2}$ is almost decisive for $(y, z)$. But since $O$ was chosen to be of minimal size and $\hat{O}_{2}$ is smaller than ô by one element, $\hat{O}_{2}$ cannot be almost decisive. Therefore by the single-valuedness of the choice function under axiom 1 and by axiom 5 , it must be that $\mathrm{YPz}^{205}$

Now, $\mathrm{xPy} \& \mathrm{yPz} \Rightarrow \mathrm{xPz}$, by transitivity under Lemma 1 . However, $\forall c_{1}$ $\varepsilon \hat{\mathrm{O}}_{1}, \mathrm{xP}_{\mathrm{i}} \mathrm{z}$ while $\forall \mathrm{c}_{\mathrm{m}} \varepsilon \hat{\mathrm{O}}_{2} \mathrm{U} \hat{\mathrm{O}}_{3}, \mathrm{zP}_{\mathrm{m}} \mathrm{x}$. Hence, the single criterion in $\hat{O}_{1}$ is almost decisive for $(x, z)$. However, this is contrary to the assumption that $\hat{O}$ is of minimal size and contains more than one criterion. Therefore $\dot{O}$ has only one criterion in it.

Q.E.D.

4. Theorem: Axioms 1-9 cannot be simultaneously satisfied.

Proof: By combining Lemmas 4 and 5, axiom 6 must be violated.

Note that axioms I-IX in the text imply axioms 1-9 so that the theorem demonstrates that one of the textual axioms must be violated by any MCCP.296 Note also that although the theorem is stated here in terms of axioms 1-9 and not in terms of the conditions for Arrow's general possibility theorem, the theorem here is essentially Arrow's theorem. The only difference is that axioms 1-9 were used to obtain as Lemma 3 the single condition of Arrow's theorem that is not already expressed in one of the axioms or in the definition of MCCPs. ${ }^{297}$

Appendix D: List of the Nine Axioms Used in Text

This appendix lists the nine axioms that are used in the text of the article: 298

\section{Axiom I: The MCCP chooses one alternative from a pool of} alternatives.

294. $\mathrm{y} \mathrm{P}_{\mathrm{k}} \mathrm{x}$ follows from $\left[\mathrm{yP}_{\mathrm{k}} \mathrm{z}\right.$ and $\left.\mathrm{z} \mathrm{P}_{\mathrm{k}} \mathrm{x}\right]$ since the preferences under each criterion are transitive by assumption. See p. 765 supra.

295. See pp. 772-73 and notes $287 \& 292$ supra.

296. See Appendix B, pp. 768-72 supra (demonstrating that each arabic-numbered axiom is restatement of or follows from roman numeral axioms in text).

297. See pp. 765-66, 767-68 supra.

298. For an explanation of the meaning of the axioms, see pp. 720-25 supra. 


\section{Multicriteria Choice Processes}

2. Axiom II: There are at least three "potential alternatives," each of which would be chosen if available and if no better alternative were a possible choice.

3. Axiom III: The choice process can consider any conceivable "potential alternative" regardless of its particular characteristics.

4. Axiom IV: The MCCP uses no absolute scales or absolute weights to combine categorical rankings into a choice.

5. Axiom $V:$ Given any two alternatives $A$ and $B, A$ will be $a$ more desirable alternative than $B$, or $B$ will be a more desirable alternative than $A$, or $A$ and $B$ will be equally desirable alternatives. The more desirable of the two must be chosen if one is more desirable than the other.

6. Axiom VI: No one criterion totally dominates the MCCP.

7. Axiom VII: For any set of alternatives, the choice process will have the same result whether the choice is made directly from the entire set or is made from a set of preliminary winners chosen from subsets comprising the entire set.

8. Axiom VIII: For every possible set of alternatives, if one member of the set ranks higher than a second member in every criterion used in the choice process, then the second member will not be chosen.

9. Axiom IX: For any two alternatives, $A$ and $B$, construct their comparative categorical rankings. If there are any other two alternatives, $C$ and $D$, where $C$ has the same comparative rankings relative to $D$ as $A$ has to $B$, and $D$ is not chosen over $C$, then $B$ is not chosen over $A$. 


\section{The Yale Law Journal}

Volume 88, Number 4, March 1979

Paul M. Smith

Editor-in-Chief

Edward L. Rubin

Note of Topics Editor

Stephen L. Carter

Susan L. Hoffman

Gerson A. Zweifach

Note Editors
Lee J. Levine

Managing Editor

Kim J. Landsman

Martha L. Minow

James F. Strnad II

Article is Book Review

Editors

Sheldon S. Adler
Michael J. Album
Joel S. Beckman
Daniel J. Broderick
Donald F. Brosnan
James J. Brudney
Sarah E. Burns
William C. Campbell
Peter C. Canfield
William W. Chip
Alice Armitage Colburn
Lant B. Davis
David W. Ferguson

Sheldon S. Adler

Michael A. Fitts

Eric M. Freedman

A. Ann Fruman

Courtney W. Howland

Gary S. Katzmann

Reinier H. Kraakman

Bruce R. Kraus

John J. Kulewicz

William L. Lynch

Sonia Sotomayor

de Noonan

Karen L. Peterson

\author{
Joseph J. Sheehan \\ John H. Small \\ Michael G. Starr \\ Susan P. Sturm \\ Bruce C. Swartz \\ Gary C. Tepper \\ Daniel M. Waggoner \\ Anne S. Wallwork \\ Richard C. Weisberg \\ Ellen Wertheimer \\ David J. Wohlberg \\ Robert R. Wootton \\ Ellen E. Wright
}

Secretaries to the Editors M. Olive Butterfield, Pamela Willmott

\section{Student Contributors to This Issue}

Lant B. Davis, John H. Small, and David J. Wohlberg, Suing the Police in Federal Court

Sonia Sotomayor de Noonan, Statehood and the Equal Footing Doctrine: The Case for Puerto Rican Seabed Rights

Gary C. Tepper, Procedural Safeguards for Periodic Review: A New Commitment to Mental Patients' Rights

Anne S. Wallwork, Antidiscrimination Class Actions Under the Federal Rules of Civil Procedure: The Transformation of Rule 23(b)(2) 